Available online at:

https://acta-acustica.edpsciences.org

\title{
Design of an in-duct micro-perforated panel absorber for axial fan noise attenuation
}

\author{
Sebastian Floss ${ }^{2,}$, Felix Czwielong ${ }^{1}$, Manfred Kaltenbacher ${ }^{2,3}$, and Stefan Becker ${ }^{1}$ \\ ${ }^{1}$ Institute of Process Machinery and Systems Engineering, Friedrich-Alexander-University Erlangen-Nürnberg, \\ 91054 Erlangen, Germany \\ ${ }^{2}$ Institute of Mechanics and Mechatronics E325-3, TU Wien, 1040 Vienna, Austria \\ ${ }^{3}$ Institute of Fundamentals and Theory in Electrical Engineering, TU Graz, 8010 Graz, Austria
}

Received 18 May 2020, Accepted 9 April 2021

\begin{abstract}
The reduction of fan noise in ducts is a challenging task for acoustic engineers. Usually, the confined space where an absorber can be integrated is small. In addition, one has to consider the influence of the absorber on the flow field and the attenuation of noise should be as great as possible. In this contribution, we investigate the application of a micro-perforated absorber (MPA) in the direct vicinity of a low-pressure axial fan operating at low Mach number conditions. The micro-perforated plates (MPP) are modeled using the Johnson-Champoux-Allard-Lafarge (JCAL) model for porous materials. The entire geometrical setup of duct, fan and MPA is then simulated with the Finite Element (FE) method; the pre-processing effort is reduced by using non-conforming grids to discretize the different regions. The influence of the cavity length and the positioning of the fan are analyzed. The results are then applied to the construction of a full-sized MPA duct component that takes the limited space into consideration. Simulation results and overall functionality are compared to experimental results obtained in an axial-fan test rig. The Finite Element framework proved to be robust in predicting overall sound pressure level reduction in the higher volume flow rates. It is also shown that the MPP increases sound reduction in the low-frequency regime and at two resonant frequencies of the MPA setup. However, its main benefit lies in maintaining the efficiency of the fan. The location of the fan downstream or within the MPA has a significant effect on both the simulated and measured sound reduction.
\end{abstract}

Keywords: Axial fans, Micro-perforated plate, Finite element method, Noise attenuation, Equivalent fluid, Duct acoustics

\section{Nomenclature}

B Backward skewed axial fan

BPF Blade passing frequency

$c_{0}$

CAA

CAD

CFD

$\mathrm{CFS}++$

$C_{\mathrm{p}}$

DES

$D_{\text {duct }}$

$D_{\text {fan }}$

$D_{\mathrm{MPP}}$

$D_{\text {tube }}$

$\mathrm{F}$

Computer-aided design

Coupled field simulation

Specific heat of air

Detached Eddy simulation

Duct diameter

Total fan diameter

Forward skewed axial fan
Speed of sound at standard ambient conditions

Computational aeroacoustics

Computational fluid dynamics

Duct diameter of MPP duct

Inner diameter of impedance tube

$\begin{array}{ll}\mathrm{FE} & \text { Finite Element } \\ f & \text { Frequency } \\ f_{\mathrm{BPF}} & \text { Blade passing frequency of the fan } \\ f_{\mathrm{c}} & \text { Cut-off frequency } \\ f_{\text {mid }} & \text { Center frequency of noise frequency band } \\ \widetilde{K} & \text { Equivalent bulk modulus } \\ \kappa & \text { Thermal conductivity } \\ k_{0} & \text { Viscous permeability } \\ k_{0}^{\prime} & \text { Thermal permeability } \\ L_{\mathrm{c}} & \text { Cavity depth } \\ L_{\mathrm{d}} & \text { Distance from nozzle to fan hub center } \\ L_{\mathrm{MPA}} & \text { Length of MPA section (expansion chamber) } \\ L_{\mathrm{P}} & \text { Sound pressure level } \\ \mathrm{Ma} & \text { Mach number } \\ \mathrm{MFS} & \text { Short MPA duct with free inflow } \\ \mathrm{MFL} & \text { Long MPA duct with free inflow }\end{array}$

*Corresponding author: sebastian.floss@tuwien.ac.at 


$\begin{array}{ll}\text { MPA } & \text { Micro-perforated absorber } \\ \text { MPP } & \text { Micro-perforated panel } \\ n & \text { Integer multiples } \\ \text { NACA } & \text { National Advisory Committee for Aeronautics } \\ n_{\text {rot }} & \text { Number of revolutions } \\ \tilde{\rho} & \text { Equivalent density } \\ p_{\mathrm{a}} & \text { Acoustic pressure } \\ \text { PML } & \text { Perfectly matched layer } \\ \text { RFS } & \text { Short reference duct with free inflow } \\ \text { RFL } & \text { Long reference duct with free inflow } \\ R_{\text {Mic }} & \text { Radius of the microphone setup } \\ \text { TL } & \text { Transmission loss } \\ \lambda & \text { Wavelength } \\ \Phi_{\text {Mic }} & \text { Angle between microphones } \\ \dot{V} & \text { Volume flow rate } \\ \omega & \text { Angular frequency } \\ \alpha_{\infty} & \text { High frequency limit of tortuosity } \\ \epsilon & \text { Correction length } \\ \Lambda & \text { Viscous characteristic length } \\ \Lambda^{\prime} & \text { Thermal characteristic length } \\ r & \text { Hydraulic pore radius } \\ \Phi & \text { Porosity } \\ \gamma & \text { Isentropic exponent } \\ \eta_{0} & \text { Dynamic viscosity }\end{array}$

\section{Introduction}

The sound emission spectrum created by an axial fan operating at low Mach number conditions is influenced by various mechanisms. Inhomogeneous inflow leads to an increase in unsteady blade forces [1-3]. Most obviously, this is the case for the blade passing frequency $f_{\mathrm{BPF}}$, where elongated and stretched eddies are cut multiple times by consecutive fan blades. Due to the high spatial coherence of circumferential flow distortions, a tonal sound is produced and emitted at high levels. On the other hand, flow with a higher turbulent intensity and thus more randomly fluctuating velocity components, leads to a more broadband noise spectrum [4]. A first step in reducing sound emission would be to change the shape of the fan blades, e.g. skewed forward or backward, or even to add serrations, slits or porous materials to the leading or trailing edge of the blades [4-9]. However, adding passive sound absorbing structures is beneficial to overall in-situ performance as well as costefficient through further reduction of sound emission. They should be compact due to the limitation of space and have a minimal influence on the flow field $[7,10,11]$. Therefore, we propose the application of an expansion chamber lined with micro-perforated plates on the circumference of the duct in the direct vicinity of the axial fan. In a smaller geometry scale study, Lee [12] showed the effect of various cylindrical micro-perforated duct elongations in a limited frequency range, mainly the blade passage frequency regime. His main focus was the investigation of flow resistance variations of customized micro-perforated material. Allam and Åbom [13] used MPPs as a shroud for the reduction of sound in automotive radiator cooling fans and as splitter type silencers for fan noise control [14]. In [15] Sacks and Åbom introduced modal filters based on MPPs for medium frequency sound absorption of the tonal noise of a compressor. He realized a two-stage duct silencer by applying additional MPPs in a starlike arrangement within a circular shaped duct to specifically dampen higher order spinning modes. The same MPP arrangement was tested on an axial fan in [16], where they showed the effectiveness of such a design on the reduction of emitted fan noise. To avoid an additional effect on the inflow conditions of the fan and thus an unfavorable contribution to extra noise generation, a similar design was not considered.

The central questions investigated in this contribution deal with the accuracy of the Finite Element (FE) based simulated sound emission spectra compared to experimental data obtained in a specifically-designed large-scale test rig. Also, the MPA structure's influence, with its manufacturing imperfections, on the characteristic curves of the fan performance is of interest.

The paper is structured as follows. In Section 2 the simulation framework is established, dealing with obtaining micro-perforated plate material parameters and modeling the micro-perforated plate as an equivalent fluid. The meshing is facilitated using non-conforming Finite Elements. Also the experimental setup and a selection of MPA investigated structures are described (cf. [17, 18]). In Section 3 the simulation results of the MPA configurations are compared to measured data. The effects of the fan positioning and the cavity depth on overall sound pressure levels are discussed, as well as acoustic source location on sound directivity in the simulation. Furthermore, a description of the experimental setup is presented. At the end, fan efficiency, pressure rise and accumulated sound emission curves with and without MPA are compared.

\section{Prerequisites to design and simulation}

The main difference between the micro-perforated panel absorber and conventional liners is that sound absorption only takes place in a thin domain of frame material perforations. Acoustic kinetic energy of a standing wave reaches a peak at a distance $L_{\mathrm{c}}=n \lambda / 4(n=1,3,5, \ldots)$ from the sound hard end piece of the cavity (cf. Fig. 2a) and induces velocity-proportional friction losses (cf. e.g. [19]). The wavelength $\lambda$ is derived from $c_{0}=f_{\text {mid }} \lambda$, with the speed of sound $c_{0}$, where $f_{\text {mid }}$ determines the center frequency of an identified noise spectrum that should be attenuated. For a frequency domain FE simulation, the first step is to acquire accurate material parameters of the perforated sound-absorbing material. Two principal parameters govern the acoustic absorption behavior: porosity and the characteristic length of the perforations. The commercially-available sheet material investigated consists of slitshaped perforations due to the manufacturing process. However, the theoretical model applied is based on circularshaped perforations (cf. e.g. [20]). Usually, manufacturers can give rough estimates of the porosity. Pore dimension 


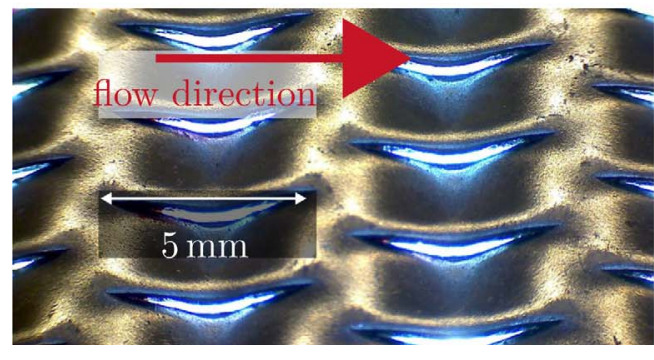

(a)

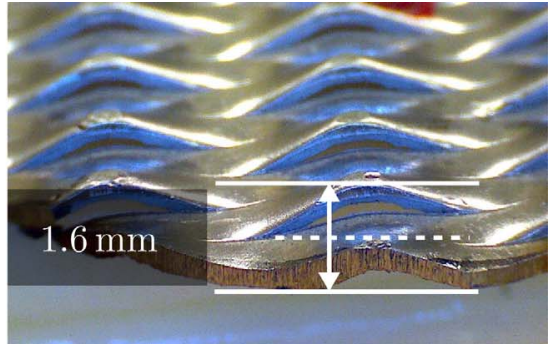

(b)

Figure 1. Micro-perforated sheet material: Acustimet ${ }^{\mathrm{TM}}$. (a) Top view of the MPP specimen. (b) Side view of the MPP specimen.

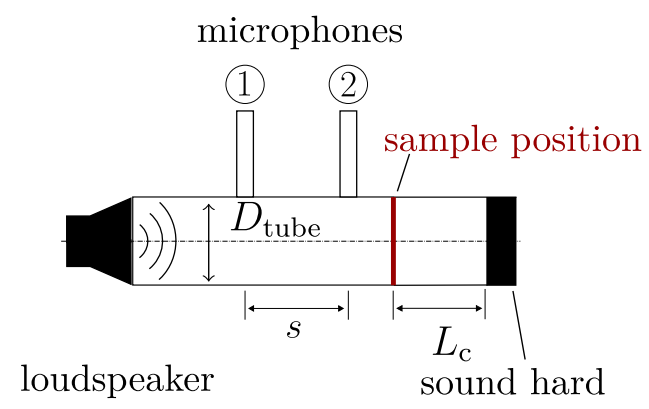

(a)

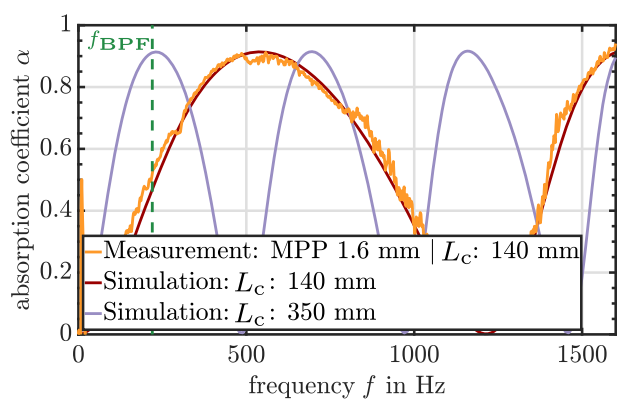

(b)

Figure 2. Sheet material parameter characterization. (a) Impedance tube with MPP specimen. (b) Absorption curve of MPP with indicated $\mathrm{BPF}$ of the axial fans.

measurement uncertainty depends on the precision of the applied measurement device (e.g. a high-resolution camera).

\subsection{Material}

The basis of the MPA is a stainless steel metal sheet with slit-shaped perforations. The material's production process is well-established and it has shown comparable absorption behavior to fibrous and porous bulk material [21], and yet the MPP is fire-proof and fiber-free. Additionally, steel allows welding, which is of importance when dealing with a circumferential arrangement and a small margin of error for the circularity (cf. Fig. 4b). The remaining welding seam retaining the MPP sheet's cylindrical shape must have a minimal height, otherwise the blades of the fan would be damaged. Figure 1 shows the top and the side view of the material indicating the thickness and the characteristic length parallel to mean flow direction. The flow structures' radial velocity component due to blade acceleration would point into the page plane. The slits have a length of $5 \mathrm{~mm}$ measured with a high-resolution camera and the MPP in front of an LED light source. The MPPs thickness is approximately $1.6 \mathrm{~mm}$. The thickness, in particular, is hard to measure due to the waviness of the surface. The manufacturer specifies the sheet as semi-finished good with a thickness of $0.55 \mathrm{~mm}$.

\subsection{Modeling and parameter fitting}

The simulation framework is based on solving (1) for the acoustic pressure $p_{\mathrm{a}}$ in an inhomogeneous (cf. [22, 23]) spatially-descretized domain with the Finite Element (FE) method (cf. [24]). Thereby, the simulation of the MPP's absorption behavior does not depend on the real material's principal parameters, but on equivalent parameters obtained via data-fitting,

$$
\frac{\omega^{2}}{\tilde{K}} p_{\mathrm{a}}+\nabla \cdot\left(\frac{1}{\tilde{\rho}} \nabla p_{\mathrm{a}}\right)=0 .
$$

In (1), $\omega$ is the angular frequency, $\tilde{\rho}$, the equivalent fluid density and $\tilde{K}$, the equivalent bulk modulus determining the material's frequency absorption response. In the air region, the effective material parameters take on the values of $\rho_{0}$ and $K_{0}$ according to the properties of air. Now for modeling the MPP, we make use of Johnson-ChampouxAllard-Lafarge's model (JCAL, cf. [25]) and condense the real material's frequency-depended acoustic absorption behavior into an equivalent volume region in the $\mathrm{FE}$ domain having isotropic-volume-averaged material properties. The model is of the semi-empirical kind, meaning that low- and high-frequency limiting parameters must be known. The behavior between those two extrema is interpolated by a mathematical model. The low frequency limit is the static flow resistance. At higher frequencies the 
tortuosity sets the limit. The basic physical parameters can be derived from the micro-structure length scales of a porous material. These parameters are:

- Tortuosity in the high-frequency limit $\alpha_{\infty}$ : States how strong the orientation of the pores deviates from a right angle. Thereby, the thickness of the plate $h$ has to be corrected for flow distortions near the perforations with a correction length $\epsilon$ and $\alpha_{\infty}=1+2 \epsilon / h$. A more detailed model description can be found in [26]. The effective density in the high frequency limit is $\tilde{\rho}=\alpha_{\infty} \rho_{0}$.

- Viscous characteristic length $\Lambda$ : Represents, in effect, the surface-to-pore-volume ratio where each volume element is weighted according to the local bulk pore velocity potential field. Viscous effects are located in a very small region close to the solid walls of the pore.

- Thermal characteristic length $\Lambda^{\prime}$ : Surface-to-porevolume ratio without local velocity weighting.

- Static thermal permeability $k_{0}^{\prime}$ : Reflects thermal permeability at low frequencies as $k_{0}$ does for viscous permeability when the size of the thermal boundary layer is of the order of the pore size. In contrast to static flow resistance, it is independent of the fluid itself. For the thin MPP, it is assumed that $k_{0}=k_{0}^{\prime}$.

The Equivalent density and the bulk modulus are thereby calculated from (cf. [26]),

$$
\begin{gathered}
\tilde{\rho}(\omega)=\frac{\alpha_{\infty} \rho_{0}}{\phi}\left[1+\frac{\sigma \phi}{j \omega \rho_{0} \alpha_{\infty}} \sqrt{\left.1+j \frac{4 \alpha_{\infty}^{2} \eta_{0} \rho_{0} \omega}{\sigma^{2} \Lambda^{2} \phi^{2}}\right]}\right] \\
\tilde{K}(\omega)=\frac{\gamma p_{0} / \phi}{\gamma-(\gamma-1)\left[1-j \frac{\phi \kappa}{k_{0}^{\prime} C_{\mathrm{p}} \rho_{0} \omega} \sqrt{1+j \frac{4 k_{0}^{\prime 2} C_{\mathrm{p}} \rho_{0} \omega}{\kappa \Lambda^{\prime 2} \phi^{2}}}\right]^{-1}} .
\end{gathered}
$$

In (2) and (3), $\rho_{0}$ denotes the mean density of air at standard ambient conditions, $\phi$, the porosity, $\sigma$, the specific flow resistance, $\Lambda$, the viscous and $\Lambda^{\prime}$, the thermal characteristic length. In the case of the thin metal sheet material, the last two parameters are of the order of the characteristic length (diameter) of the pores. Furthermore, $\eta_{0}$ is the dynamic viscosity, $\kappa$ is the thermal conductivity, $\gamma$, the isentropic exponent and $C_{\mathrm{p}}$ is the specific heat of air at constant ambient pressure. An overall description of the model parameters can be found in $[25,26]$. The influence of a grazing flow or a bias flow in radial direction from the fan was not considered in the design stage due to the low Mach numbers $\left(\mathrm{Ma}=\frac{\left(n_{\text {rot }} / 60\right) \pi D_{\text {fan }}}{c}=0.11\right)$.

In a next step, a sheet material specimen is studied in an impedance tube measurement device according to [27]. The measurement setup is depicted in Figure 2a, displaying a tube schematic view with the microphone distance $s=50 \mathrm{~mm}$, the MPP (indicated in dark red) and the back volume cavity length $L_{\mathrm{c}}$. In such a tube, plane wave fronts with phase parity up to $1600 \mathrm{~Hz}$ can propagate. A general challenge of measuring the specimens in a impedance tube is visible in Figure 2b: thin plate structures vibrate due to eigenfrequency excitation by the impinging sound waves (yellow curve with small rises and dips). This would result in small band absorption peaks due to the relative motion of the MPP frame to the air volume passing the pore (more pronouncedly visible in a small tube $\left(D_{\text {tube }}=29 \mathrm{~mm}\right)$ arrangement). However, the large specimen diameter used $\left(D_{\text {tube }}=100 \mathrm{~mm}\right)$ seems to suppress such absorption behavior.

To determine the parameters $\tilde{\rho}$ and $\tilde{K}$ in (2) and (3), the absorption curve that is generated by a sheet material specimen with distance $L_{\mathrm{c}}$ (cf. Fig. 2b yellow line) is measured. By using 2-pole-network theory (transfer function method, for details cf., e.g. [28]), one can match the absorption measured with that simulated with the JCAL (cf. Fig. 2b, continuous red line) [29]. The calculations were made with (4) and (5), where the effective surface impedance $Z_{\text {eff }}$ of MPP (index 1) plus air cavity (index 0) in Figure 2a is represented by the scattering matrix $\boldsymbol{T}_{\text {eff }}$. For the MPP domain, $\boldsymbol{T}_{\mathrm{m}}$ is built by complex frequency-dependent values for $\tilde{\rho}$ and $\tilde{K}$ (for air without significant absorption, the values for the density and the bulk modulus are taken from the standard ambient conditions and have only a constant real part). The fitting quantity $\alpha$ can then be computed according to (4),

$$
\begin{gathered}
\tilde{Z}_{m}(\omega)=\sqrt{\tilde{\rho}_{m}(\omega) \tilde{K}_{m}(\omega)}=\frac{T_{m, 11}}{T_{m, 21}} ; \quad m=0,1 ; \\
\alpha=1-\left|\frac{Z_{\text {eff }}-Z_{0}}{Z_{\text {eff }}+Z_{0}}\right|^{2}
\end{gathered}
$$

$$
\begin{gathered}
\boldsymbol{T}_{\text {eff }}=\left[\begin{array}{ll}
T_{11} & T_{12} \\
T_{21} & T_{22}
\end{array}\right]=\boldsymbol{T}_{1} \cdot \boldsymbol{T}_{0} \\
\boldsymbol{T}_{m}=\left[\begin{array}{cc}
\cos \left(k_{m} h_{m}\right) & j Z_{m} \sin \left(k_{m} h_{m}\right) \\
j \frac{1}{Z_{m}} \sin \left(k_{m} h_{m}\right) & \cos \left(k_{m} h_{m}\right)
\end{array}\right] .
\end{gathered}
$$

In (5), $h_{m}$ represents the thickness of the acoustic medium, and $k_{m}$, its wavenumber. The model parameters which tune the absorption curve are the characteristic pore lengths $\Lambda^{\prime}$, $\Lambda$ and the porosity $\phi$. As mentioned before, the determination of these parameters for the slotted MPP sheet are very cumbersome. However, they are very easy to obtain dealing with a theoretical material made of circular pores with periodical distribution. In this case, the pore radius $r$ for $\Lambda^{\prime}$ and $\Lambda$ and the circular pore's surface ratio to the entire plate surface area $(\phi)$ can be chosen. It must be emphasized that for MPPs, a simulation based on absorption characterization seems to be sufficient because they are very thin. Matching complex valued material parameters to absorption means loss of information (no phase information), thus the fitting could be ambiguous. If there is no wave propagation other than in the direction of the MPP thickness, no or negligible additional phase information errors due to wave propagation in the complex valued material domain perpendicular to incident wave direction are introduced (cf. [22]). 


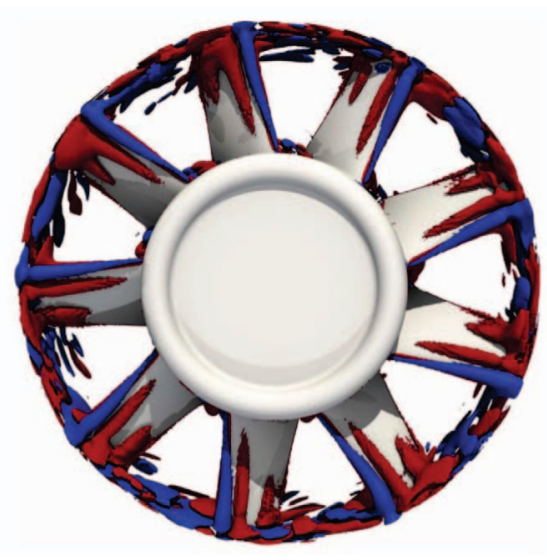

(a)

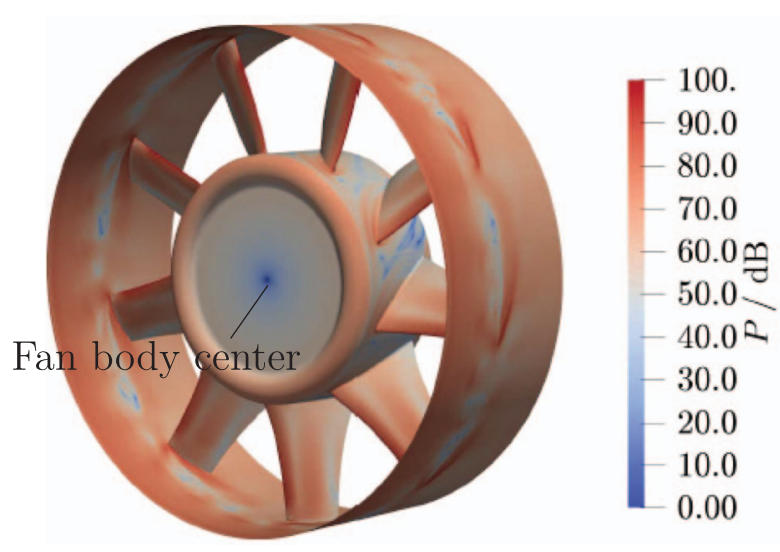

(b)

Figure 3. Constant iso surfaces of the acoustic power source terms at $220 \mathrm{~Hz}$ and surface source power levels obtained from aeroacoustic simulation of an unskewed fan, [34]. (a) Source strength iso surfaces at $220 \mathrm{~Hz}$ near $f_{\mathrm{BPF}}$. (b) Surface source acoustic power levels in $\mathrm{dB}$, calculated stochastically in time domain.

Additionally, the fitting simulations have shown that in the case of the thin metal MPP specimen, absorption is dominated by $\tilde{\rho}$ and the influence of the equivalent bulk modulus can be disregarded.

Another benefit of the impedance tube measurements comes with comparing absorption curves of different cavity length $L_{\mathrm{c}}$. With the major design parameter for dimensioning the MPA being the blade passing frequency, it is possible to pre-select an optimal cavity length. Due to its sources' coherent nature, the noise level emitted in the vicinity of the $\mathrm{BPF}$ will be very high. The blade passage frequency for the fan $(\mathrm{s})$ investigated is $f_{\mathrm{BPF}}=222.9 \mathrm{~Hz}$ (cf. green dashed line in Fig. 2b), computed by $f_{\mathrm{BPF}}=$ $n \cdot n_{\text {rot }} / 60$, with number of blades $n=9$ and a rotational speed $n_{\text {rot }}=1486 \mathrm{rpm}$. As plotted in Figure 2b, the optimal cavity length $L_{\mathrm{c}}$ with the largest absorption at the blade passing frequency would be $350 \mathrm{~mm}$. However, this contradicts the given constraint of $L_{c, \max }=200 \mathrm{~mm}$ due to space limitations at the test rig.

\subsection{Acoustic sources}

The simulation framework proposed is not CAA, since resolving the MPP spatially within CFD simulations is unfeasible for parameter studies. The exact strength and distribution of acoustic sources remains unknown. To reflect the nature of aeroacoustic noise realistically, the distribution of sources for an axial fan in a duct was investigated.

A theory of aeroacoustic analogies was first developed by Lighthill in [30], where he introduced the idea of replacing the flow field of a free unbounded jet with a sum of elementary sources. The resulting equation has the same form as the wave equation governing propagation of sound emitted by a quadrupole source with the strength of the turbulence stress tensor (Lighthill tensor) in a non-moving medium [31]. Thereby, he was able to calculate the sound power emitted and sound wave propagation into the far field. Curle [32] gave a more general derivation of the governing inhomogeneous wave equation by including in it mass sources and external forces in the governing inhomogeneous wave equation, giving a formal solution to Lighthill's equation, which takes solid surface effects into account [4]. Due to the flow's reaction forces on the blades' surface and the duct walls, dipole source behavior might be observed. Curle and Ffowcs-Wiliams and Hawkings [32, 33] state that, at low Mach numbers, compact sources can be assumed and the contribution to the sound field from the dipoles should be greater than from the quadropoles induced by the second spatial derivation of the Lighthill tensor. Thus, the source terms for the solution of (1) might be mimicked by dipole like point sources near the blade tips and the duct surface.

The fan test setup investigated was the basis for various computational aeroacoustic simulations and testing of different formulations of the inhomogenous wave equation [34]. Here, the fan was also revolving at $n_{\text {rot }}=1486 \mathrm{rpm}$. Figure 3 shows constant isosurfaces at $220 \mathrm{~Hz}$ with phase and opposite phase parity that reveal predominant equivalent sources in the tip gap region. Also, the surface sources computed according to Curle reveal that the largest power levels occur at the leading edges of the blades and at the duct in the tip gap region. Seen from the simulations in [34], leading edge noise might also add to the the tonal components at the blade passage frequency. The shown simulation results from Figure 3 [34] are based on DES CFD simulations and took up to several weeks to be completed. This corroborates unfeasability for a parameter study, since the additional disretization effort needed for microperforations would increase simulation time even further.

Combined with the theory mentioned these simulation results led to the decision to mimic the equivalent sources and location by placing point sources at a small distance from each other near the tip of the blades (cf. black points 


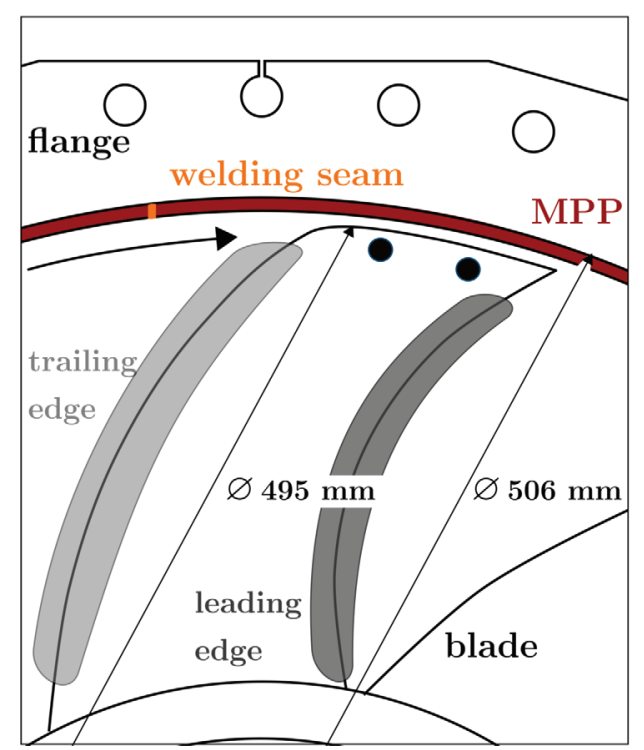

(a)

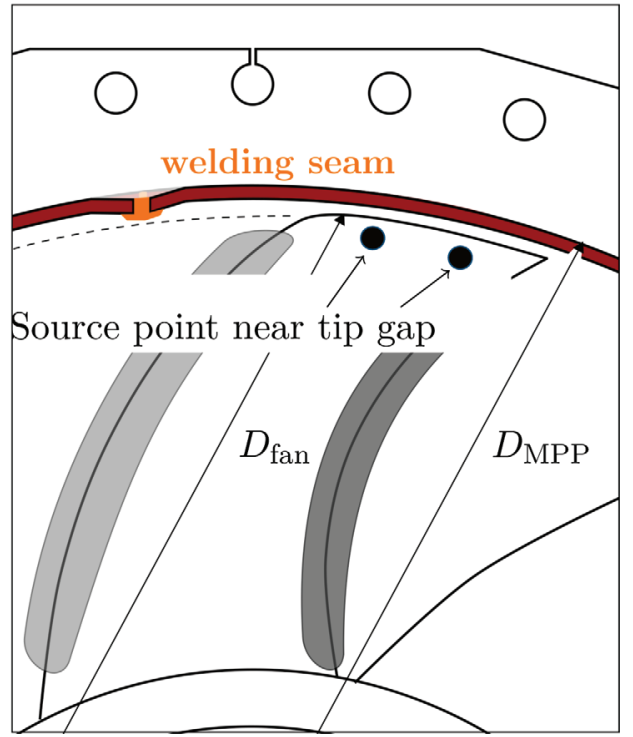

(b)

Figure 4. Dimensions and detail of the tip gap region of a fan with forward skewed blades (F); front view. (a) Ideal joint MPP sheet. (b) Constructed joint with a constricted tip gap; source points indicated.

in Figs. 4a and 4b) and solve (1). The sources were placed on the blade tip region's surface $10 \mathrm{~mm}$ from the tip edge to direct acoustic radiation towards the probe chamber. To reflect the circumferential spatial distribution of the equivalent sources (cf. Fig. 3), the point sources were placed on each of the nine blades (cf. Fig. 4b). The acoustic power emitted by the axial fan was estimated at $\approx 94 \mathrm{~dB}$ for the design point of the fan characteristic, with a volume flow rate of $1.4 \mathrm{~m}^{3} \mathrm{~s}^{-1}$ and an average pressure rise of $150 \mathrm{~Pa}$ according to [35]. This value was used as source excitation strength for the point sources on the blades to solve (1).

The simulations showed no difference in using monopole (single point)-like or dipole (two points separated by a small distance)-like in the tip gap region. A significant difference manifests if one point source of the same strength as nine distributed sources on the blades in the tip gap region (cf. Fig. $4 \mathrm{~b}$ ) is placed at the center of the fan body (cf. Figs. 3b and 11a).

\subsection{Finite element framework}

The material characterization in Section 2.2 provided MPP absorption behavior information in the frequency domain up to $1600 \mathrm{~Hz}$. The cavity length of $L_{\mathrm{c}}=140 \mathrm{~mm}$ proved to be a good compromise between a wide absorption frequency band and a high peak absorption performance with reasonable cavity length. Comparing Figure 2b, one can see the larger the cavity length, the narrower the absorption frequency bands. To reflect the acoustic behavior of the entire test setup more realistically, an FE simulation was conducted. Therefore, the duct section with fan and part of the sound-receiving air space were spatially discretized. Figure 5a shows the rectangular settling chamber with the surrounding perfectly matched layer (PML), the attached nozzle section adjacent to the MPA section, and the axial fan section bordered by a second layer of PML, guaranteeing free radiation conditions on both sides of the duct. Figure $5 \mathrm{~b}$ shows an enhanced view of the non-conforming interfaces separating each of these sub-domains, which allows a much more flexible pre-processing (cf. [22]). Thereby, the open source research software openCFS $++[24,36]$ uses Nitsche-type mortaring [22] to solve (1) efficiently. Since pre-design simulations aim to find an optimal trade-off between the cavity dimension $L_{\mathrm{c}}$ and a large amount of absorption by comparing multiple simulation runs, a compromise between necessary spatial discretization and computational effort must be found. For harmonic simulations, an estimation formula for the necessary discretization exists. The relation between the element order $q$, the wave number $k$ (complex $\tilde{k}$ in MPP domain) and the spatial discretization size $h$ is provided by [37]:

$$
q+\frac{1}{2}>\frac{k h}{2}+(k h)^{1 / 3}
$$

This inequality has to be fulfilled to obtain a pre-asymptotic error reduction by increasing the order $q$ of the FE basis functions. In Figures $6 \mathrm{a}$ and $6 \mathrm{~b}$ the resulting relations according to (6) for both the air domain and MPP domain are shown. The chosen disretization of $h=0.01 \mathrm{~m}$ for the nozzle, the MPA section and the axial fan domain (cf. Fig. 5) should be sufficient. The receiving air chamber elements were meshed with $h=0.02 \mathrm{~m}$ to reduce the number of degrees of freedom even further. Due to the complex valued material, the effective speed of sound in the MPP domain (cf. Fig. 6d) is smaller than in the surrounding air (cf. Fig. 6b), which results in a smaller required 


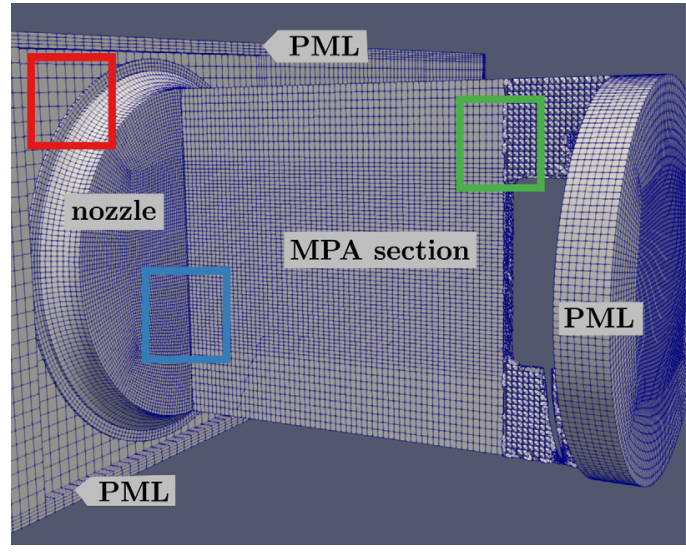

(a)
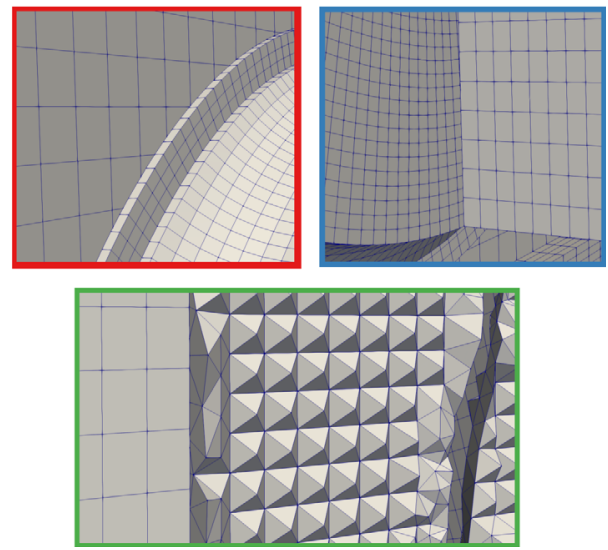

(b)

Figure 5. Finite Element subdomains with non-conforming interfaces. (a) Side view of duct axial section. (b) Enhanced view.

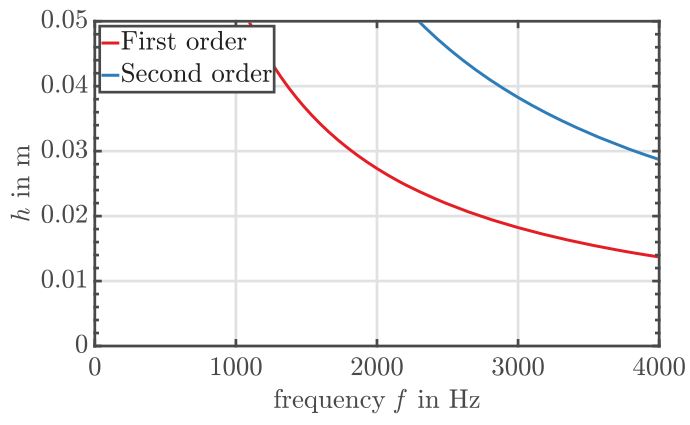

(a)

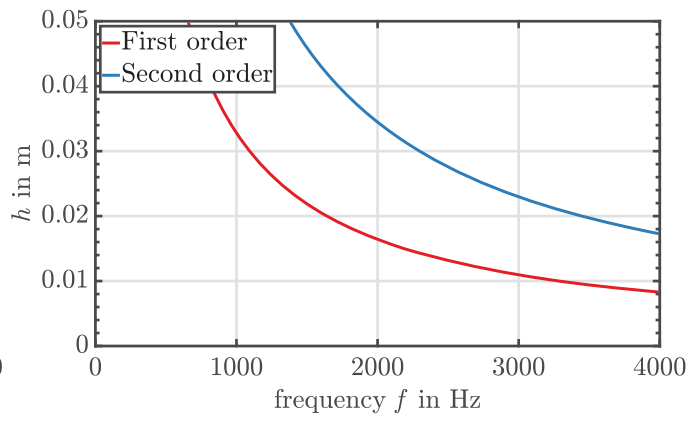

(b)

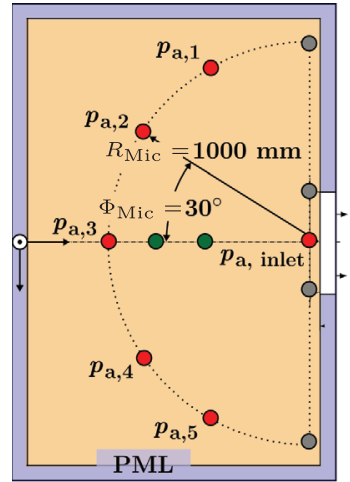

(c)
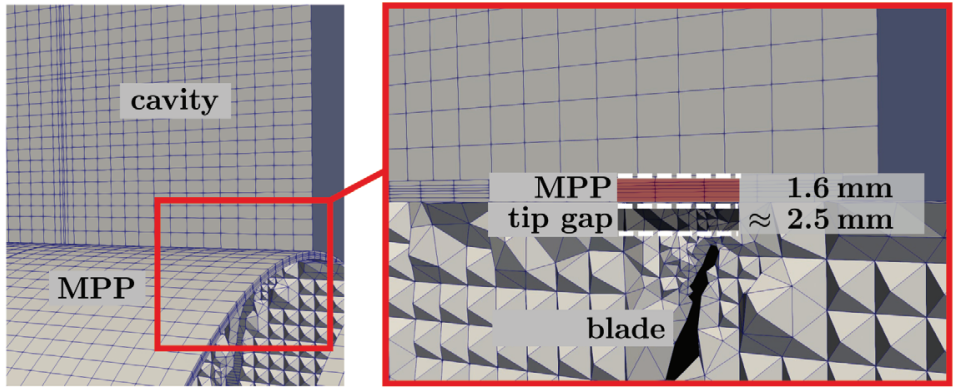

(d)

Figure 6. Discretization, monitoring points and enhanced view of MPP-cavity intersection. (a) hq-relation for air domain according to (6). (b) hq-relation for MPP domain at largest simulated frequency $1600 \mathrm{~Hz}$ with effective speed of sound of $205 \mathrm{~ms}{ }^{-1}$. (c) Pressure monitoring points in measurement plane. (d) MPP volume region with cavity enhanced view of interfaces.

discretization as the wave number increases. However, the small thickness of the domain requires an element size of less or equal to $1 \mathrm{~mm}$ in the direction of the MPP depth. Therefore, as in the rest of the computational domain, an element order of one was chosen. The sound pressure field calculated was monitored at five locations in the receiving air chamber domain (cf. Fig. 6c) and for comparison at the inlet of the nozzle. The pressure frequency results were 


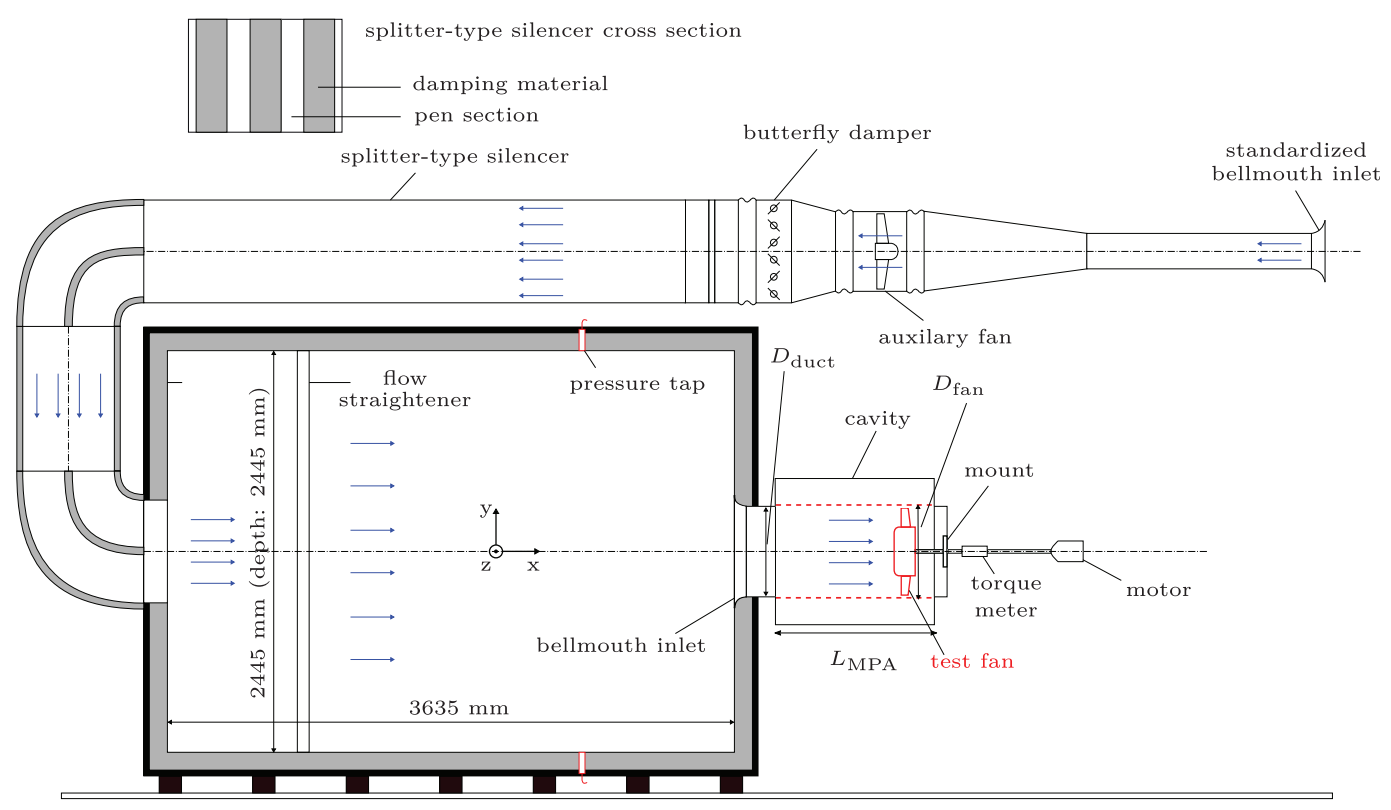

Figure 7. Inlet test chamber designed according to ISO 5801 [38].

spatially averaged and summed up to obtain an overall simulated sound pressure level $\bar{L}_{\mathrm{P} \text {.sim }}$. Each setup took roughly seventeen hours to compute on eight CPU cores with a total of 3.3 million elements.

\subsection{Inlet test chamber and MPA design}

For the comparison of the simulated data, an axial fan test rig standardized according to [38] was used. Figure 7 shows the anechoic chamber at the suction side of the test fan inlet. The air streams into the chamber through a standardized bellmouth inlet, then passes a splitter-type silencer and is afterwards straightened by a honeycomb layer. The background sound pressure level of the chamber is $L_{\mathrm{P}}=28 \mathrm{~dB}[4,39]$. The total static pressure difference of the fan can be determined by a ring pressure tap, which is connected to a differential pressure sensor to the ambience. The fan is supported by four non-centric struts, which lower the rotor-stator-interaction [4]. Outside the duct is the motor drive unit. The power and fan efficiency can be determined by comparing data from a torque meter and speed sensor with volume flow rate and static pressure difference. The sound emitted was measured with five condenser microphones covered with a flow protection screen. Three microphones (1-3) were arranged in a hemi-circle plane as depicted in Figure 6c. Microphones 4 and 5 (green in Fig. 6c) are located in a hemi-circle perpendicular to the aforementioned three and axially aligned with the duct. After the bellmouth connection to the anechoic chamber, a replacable duct section is located. This section has a length of $L_{\mathrm{MPA}}=440 \mathrm{~mm}$ and a duct diameter $D_{\text {duct }}=500 \mathrm{~mm}$ and the fan diameter $D_{\text {fan }}=495 \mathrm{~mm}$. The two latter dimensions represent the reference duct setup (tagged RFS and RFL in Fig. 8). It can be replaced by the MPA duct variant (MFS and MFL cf. Fig. 9).
Therefore, the fan examined is either operated directly in the perforated duct section (MFS) or shortly downstream in the unperforated duct section (MFL).

The relevant dimensions near the tip gap geometry are also depicted in Figure 4a. The tip gap is $\left(D_{\text {duct }}-D_{\text {fan }}\right) / 2=$ $2.5 \mathrm{~mm}$ in width for the reference cases (RFS/RFL). The setup's name acronym consists of $(\mathrm{R})$ for for reference, (F) for free inflow and (S/L) for short or long (cf. Figs. 8 and 9). Deviations from the circular circumference at the joint of the MPP sheet (cf. red area in Fig. 4b) need to be smaller than the tip gap clearance if the fan is operated above the micro-perforated sheet. The tip gap has significant influence on both the efficiency of the fan and its aeroacoustic behavior [40, 41]. First of all, the efficiency is affected because a larger tip gap leads to increased blind flow affecting the pressure rise of the fan unfavorably. On the other hand, as stated previously, the sound sources in the tip gap are the dominant ones that can occur in the subharmonic range and at higher harmonics of the blade passing frequency. A larger tip gap can amplify these source mechanisms.

For the variant $\mathrm{M}(\mathrm{pp}) \mathrm{FS}$ and $\mathrm{M}(\mathrm{pp}) \mathrm{FL}$, the perforated diameter was $D_{\mathrm{MPP}}=506 \mathrm{~mm}$ in order to make sure that no contact of the fan blades with the sheet surface irregularities occurs. This is equal to a tip gaze size enlarged by $3 \mathrm{~mm}$ compared to the reference cases (RFS/RFS). In the short (S) duct version, the fan is operated at a distance $L_{\mathrm{d}}=520 \mathrm{~mm}$ and in the long version at $L_{\mathrm{d}}=620 \mathrm{~mm}$ from the nozzle.

The investigated fans were skewed forward (prefix F) and backward (prefix B) with a NACA-profile 4510 $[4,42]$ designed for a volume flow rate $\dot{V}=1.4 \mathrm{~ms}^{-3}$ and a fan speed of $n_{\text {rot }}=1486 \mathrm{rpm}$. Their aeroacoustic behavior varies quite significantly. At the design point the forwardskewed fan is quieter. The backward-skewed fan leads to 


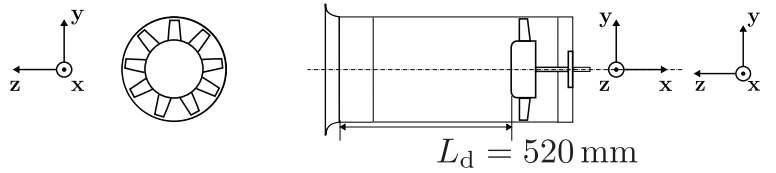

(a)
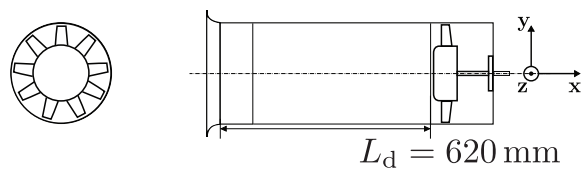

(b)

Figure 8. Schematic representation of the reference $(\mathrm{R})$ duct design. F indicates that the inflow was undisturbed and $\mathrm{S}$ and $\mathrm{L}$ stand for the short $L_{\mathrm{d}}=520 \mathrm{~mm}$ and long version $L_{\mathrm{d}}=620 \mathrm{~mm}$. (a) Reference short duct fan setup, RFS. (b) Reference long duct fan setup, RFL.

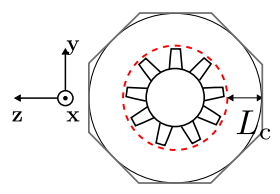

(a)
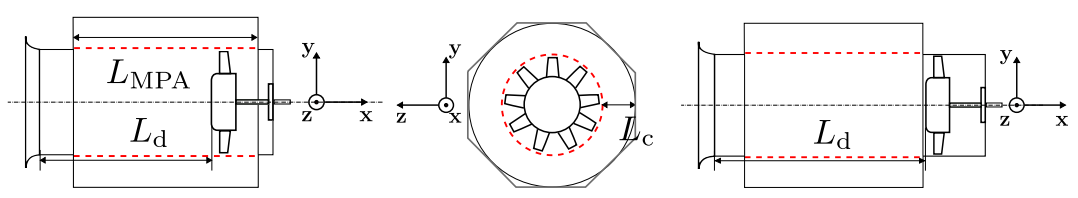

(b)

Figure 9. Schematic representation of the MPA duct design (M). Free inflow conditions (F) with long (L) as well as short (S) version (with the same length as in reference case); $L_{\mathrm{MPA}}=440 \mathrm{~mm}$ and indicated cavity length $L_{\mathrm{c}}$, cf. [15]. (a) Short MPA fan duct setup, MFS. (b) Long MPA duct setup, MFL.

larger sound sources, although the forward-skewed fan reacts more sensitively to unsteady (disturbed) inflow conditions $[43,44]$. The simulation data was compared to measured data of undisturbed inflow conditions. The influence of interaction with inflow turbulence on the MPA and fan performance can be looked up in [39].

\section{Comparison of simulation and experiments}

In this section, the overall simulated sound pressure spectra of two MPA configuration are investigated and compared to the experimental results. The effect of the MPP on sound absorption and the fan characteristic curve is demonstrated.

\subsection{Radiated sound and directivity}

A design parameter input constraint was a maximum cavity length of $L_{\mathrm{c}}=200 \mathrm{~mm}$. First, characterizing simulations of the geometry setup are shown in Figure 10. A transmission loss computation of various cavity depths with transmission line theory (expansion chamber model, cf. [45] for details) shows only minor damping effects even at $L_{\mathrm{c}}=200 \mathrm{~mm}$. An FE simulation of the entire domain without MPP but with cavity length $L_{\mathrm{c}}=200 \mathrm{~mm}$ and length $L_{\mathrm{MPA}}=440 \mathrm{~mm}$ reveals that the sound emission spectrum at the duct nozzle center adjacent to the air chamber is qualitatively represented by the overall sound pressure level at the monitoring points (similar overall sound pressure trend over frequency) up to $1000 \mathrm{~Hz}$ (cf. Fig. 10b). If we assume plane wave fronts and free radiation conditions are present, we can verify the results in Figure 10b with the radiated sound power by comparing the sound pressure levels at the center inlet (cross section area $A_{\text {duct }}$ ) and at a distance of $R_{\mathrm{Mic}}=1000 \mathrm{~mm}$ over the half-sphere surface $A_{\mathcal{D}}$ [46] by,

$$
\Delta\left(L_{\mathrm{P}, \text { inlet center }}-\bar{L}_{\mathrm{P}}\right)=10 \log \left(A_{\mathcal{D}} / A_{\text {duct }}\right) \mathrm{dB} .
$$

The sound pressure level between the center inlet microphone points and the points at distance $R_{\mathrm{Mic}}$ should decrease by about $15.1 \mathrm{~dB}$ at a $1000 \mathrm{~mm}$ distance from the nozzle inlet. This behavior is visible below $500 \mathrm{~Hz}$, near the cutoff frequency of the first circumferential mode for the RFS setup. In the MFS case, the first cut-off frequency drops from $f_{\mathrm{c}, \mathrm{RFS}}=398 \mathrm{~Hz}$ to $f_{\mathrm{c}, \mathrm{MFS}}=221 \mathrm{~Hz}$ due to additional cavity length $L_{\mathrm{c}}$. In Figures $10 \mathrm{a}$ and 10b, certain resonance frequencies are highlighted. Below $f_{\mathrm{c}, \mathrm{MFS}}=221 \mathrm{~Hz}$, all higher order modes are cut off $\left(f_{\mathrm{c}}=0.58 c_{0} / D_{\text {duct }}\right)$. At $f_{\lambda / 4,1}=190 \mathrm{~Hz}$, $f_{\lambda / 4,2}=580 \mathrm{~Hz}$ and $f_{\lambda / 4,3}=970 \mathrm{~Hz}$, the simulated TL spectra (cf. Fig. 10a) show significant dips that are associated with integer multiples of the cavity length dimension $L_{\mathrm{MPA}}$. At $f_{\lambda / 2,1}=780 \mathrm{~Hz}$, the simulated spectrum reveals an additional narrower very pronounced dip (cf. Fig. 10b). Thus, the expansion chamber expresses $\lambda / 4$ as well as $\lambda / 2$ reflection damping effects, and each should be amplified by the MPP. Additionally, the radiation strength and the directivity pattern of the reference duct with the nozzle were investigated. Figure 11a reveals that with a single point source at the fan body center at a distance from the nozzle comparable to that of the nine point sources distributed across the blade tip region, the radiation strength is generally amplified, especially above $f_{\lambda / 2}=780 \mathrm{~Hz}$. Reflection at the duct walls begins to occur as soon as higher order modes can propagate. Higher order mode wave fronts not in phase parity tend to decrease propagating sound pressure levels by canceling out each other's portions of the wave fronts. The proximity of the point sources (Fig. 4a, in reality the tip gap equivalent sources) to the duct wall will most likely influence the sources' emission effectiveness by this reflection effect, since at frequencies below the cut-off frequencies $f_{\mathrm{c}, \mathrm{RFS}}, f_{\mathrm{c}, \mathrm{MFS}}$ and $f_{\lambda / 2}$, the radiation pattern and signal strength do not differ much. 


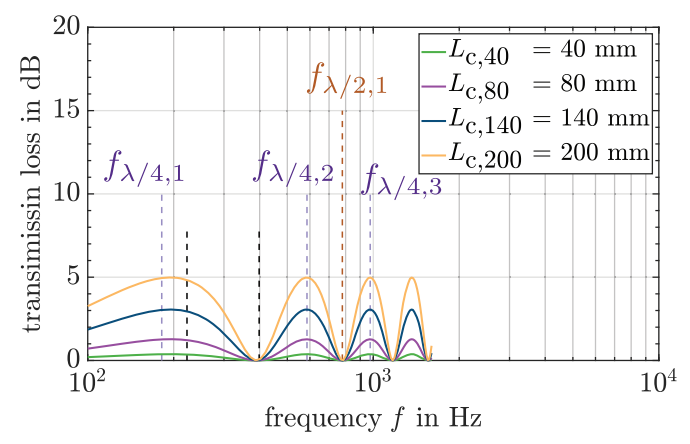

(a)

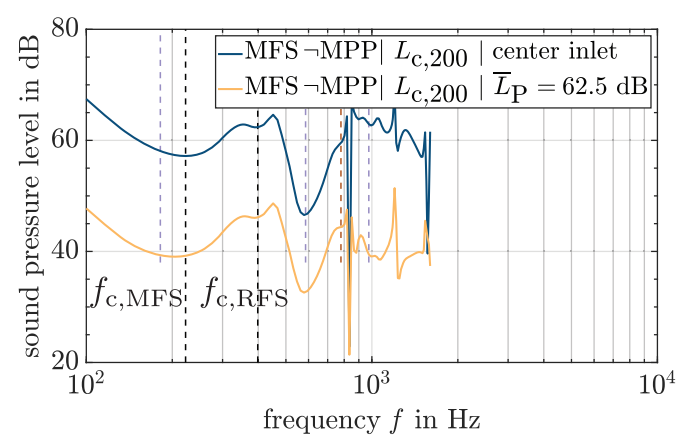

(b)

Figure 10. Pre-characterization simulations of geometry. (a) Transmission loss due to cross section changes; highlighted $\lambda / 4-$ and $\lambda / 2$-resonance frequencies. (b) Overall simulated sound pressure of the MPA setup without MPP $\bar{L}_{\mathrm{P}}$ compared to single center inlet point at the nozzle (cf. Fig. 6c); indicated cut-off frequencies $f_{\mathrm{c}, \mathrm{RFS}}$ and $f_{\mathrm{c}, \mathrm{MFS}}$.

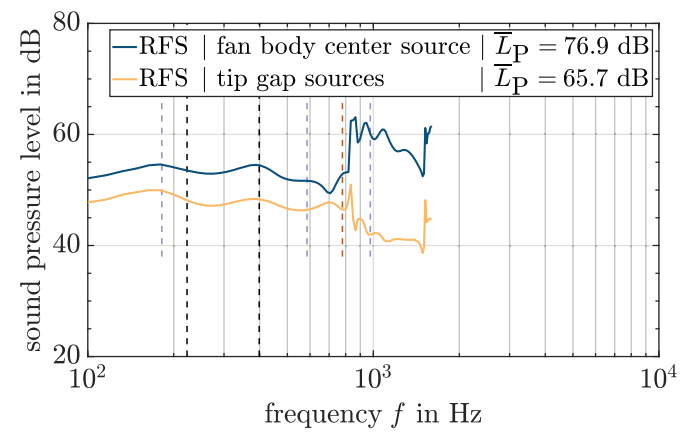

(a)

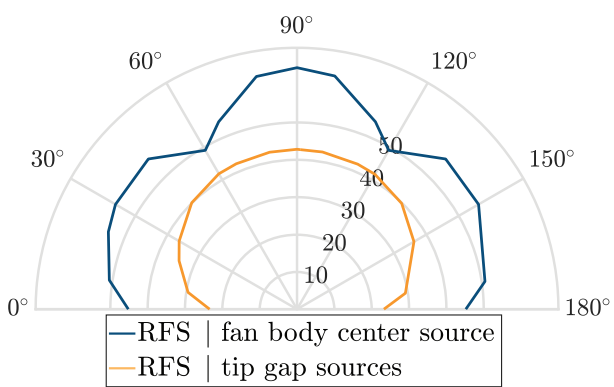

(b)

Figure 11. Simulated radiation pattern and strength of point sources located on the fan body center axis and in the blades' tip gap region. (a) Simulated sound emission spectra of varied point source location for the reference setup. (b) Simulated sound emission directivity pattern at $1200 \mathrm{~Hz}$ with sound pressure level isolines.

In Figure 11b, the more pronounced directivity pattern of the single point source far beyond the cut-off frequencies at $1200 \mathrm{~Hz}$ is depicted. Comparing Figures 10b and 11a reveals that a lower-level non-monopole directivity behavior is present, indicating the emitted spectrum's qualitative and quantitative dependence on the source positioning.

\subsection{Sound mission spectra}

The sound emission spectra of three operating points measured in RFS/FS and RFL/MFL configuration are compared with simulations. Figures $12 \mathrm{a}$ and $12 \mathrm{~b}$ show the measured spectra for a volume flow rate of $0.8 \mathrm{~m}^{3} \mathrm{~s}^{-1}$, which lies in the unsteady range of the fan characteristic curve, where aerodynamic sound sources are more dominant for the backward skewed fan (B) than for the forward skewed fan (F) (Table 1). A plausible behavior for the fan version (F) due to the forward skewness of the blades. Compared to Table 2, the overall largest sound reductions are found for the backward skewed fan and in this portion of the fan characteristic. The simulated emission spectra at
RFS/MFS reproduce the sound level trend qualitatively, but not quantitatively. The emission spectra measured are dominated by sources due to the unsteady blade forces unable to be accounted for by the simulation. The source strength was calculated at the design point of $\dot{V}=1.4 \mathrm{~m}^{3} \mathrm{~s}^{-1}$. However, with increasing volume flow rate the simulated spectra approximate measured sound emissions of the fan version (F) in the RFS and MFS setup (cf. Figs. 12c and 12e-12d and 12f). The sound level dip at $f_{\lambda / 4,2}$ is better represented by simulating a larger cavity $L_{\mathrm{c}, 200}$ (Fig. 12b). In general, the sound level dip at $f_{\lambda / 4,2}$ is more accurately represented by the simulation than at $f_{\lambda / 2,1}$. This could be caused by various effects: at the beginning of higher order mode propagation, the sound wave fronts become increasingly skewed and thus more sensitive to changes in geometry dimensions than a plane wave mode. Secondly, the geometries in the experiment and simulations are not exactly identical; the shape of the MPA was changed from cylindrical in the simulation to an octagonal shape (cf. Fig. 9) for the sake of easier and more precise construction. The differences at $f_{\lambda / 4,2}$ might also be caused 


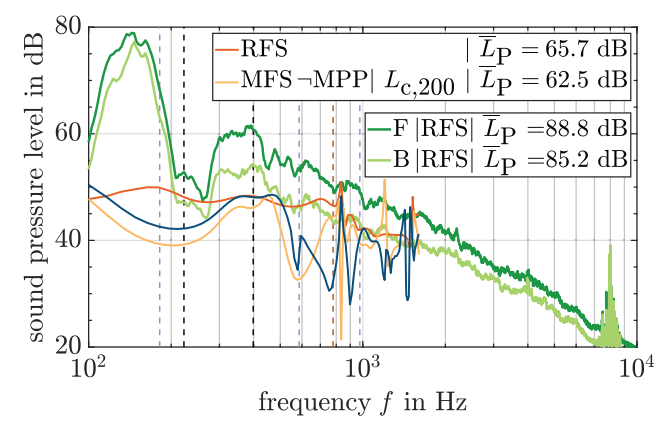

(a)

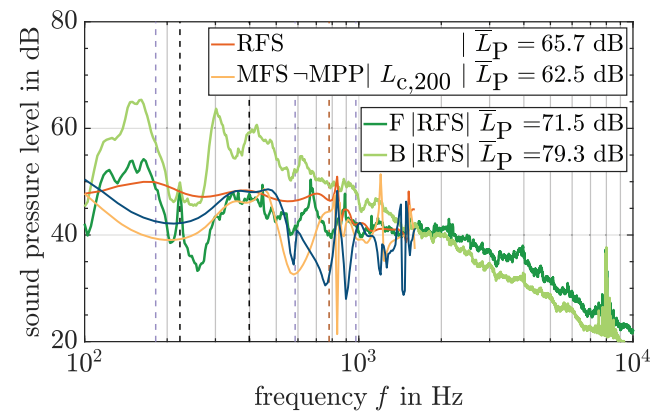

(c)

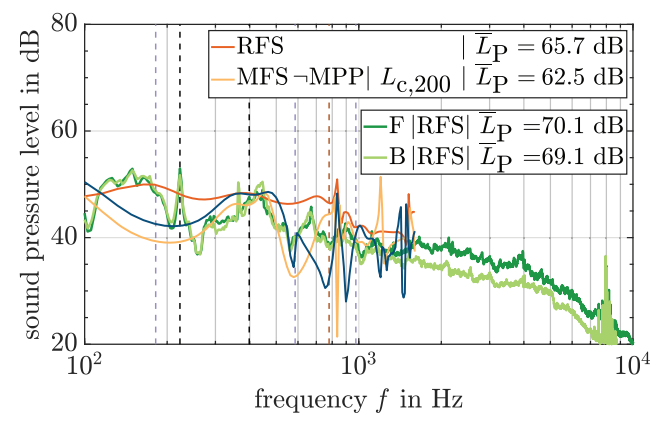

(e)

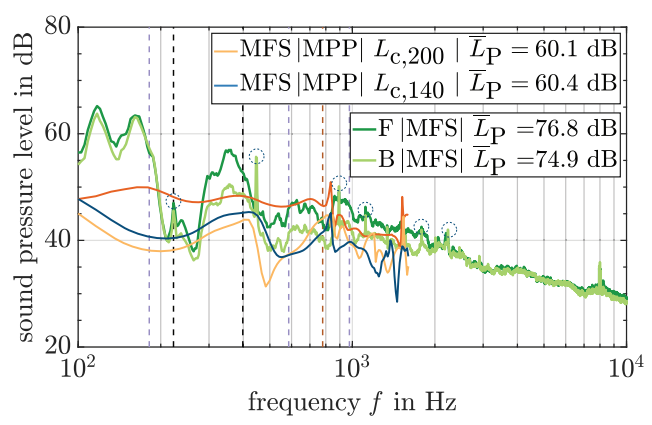

(b)

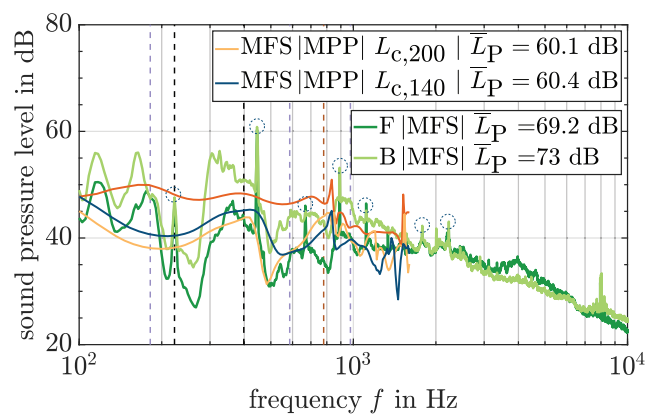

(d)

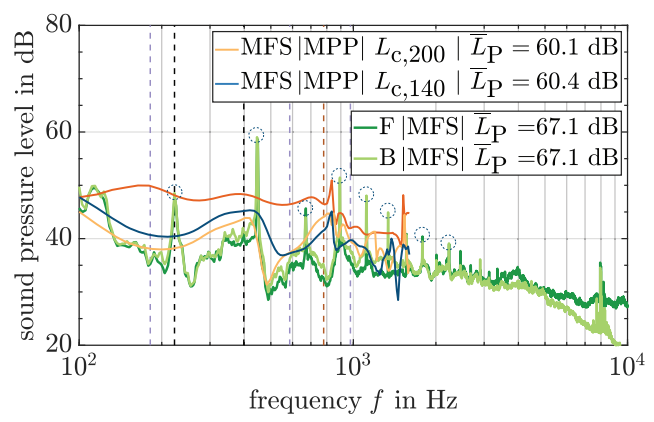

(f)

Figure 12. Measured and simulated sound emission spectra of the RFS-MFS configuration; (a, c, e) show simulated cases without MPP and in (b, d, f) the MPP is added. (a) RFS emission spectrum at $0.8 \mathrm{~m}^{3} \mathrm{~s}^{-1}$. (b) MFS emission spectrum at $0.8 \mathrm{~m}^{3} \mathrm{~s}^{-1}$. (c) RFS emission spectrum at $1.4 \mathrm{~m}^{3} \mathrm{~s}^{-1}$. (d) MFS emission spectrum at $1.4 \mathrm{~m}^{3} \mathrm{~s}^{-1}$. (e) RFS emission spectrum at $1.9 \mathrm{~m}^{3} \mathrm{~s}^{-1}$. (f) MFS emission spectrum at $1.9 \mathrm{~m}^{3} \mathrm{~s}^{-1}$.

by the acoustic boundary condition at the back wall of the cavity length $L_{\mathrm{c}}$. In the simulation, a perfectly sound hard wall can be imposed, but in reality, the aluminum back plate had a thickness of $2 \mathrm{~mm}$. The MPA could become a dispersive system, especially at the sound level dips, caused by the vibrating back plate.

The frequency shift at $f_{\lambda / 4,2}$ when adding the MPP can

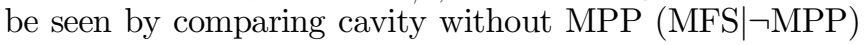
to the case with MPP applied to the cavity (Figs. 12a and $12 \mathrm{~b}$ ). Overall, the MPP adds about $3 \mathrm{~dB}$ to the sound reduction capability of the expansion chamber (cf. Table 2). In the region near the blade passing frequency $f_{\mathrm{BPF}}$ and its first harmonic (spectrum position corresponding roughly to $f_{\mathrm{c}, \mathrm{RFS}}$ and $\left.f_{\mathrm{c}, \mathrm{MFS}}\right)$, the resonance at $f_{\lambda / 4,1}$ produces large sound reduction even without the MPP. Comparing the cases of cavity lengths $L_{\mathrm{c}, 140}$ and $L_{\mathrm{c}, 200}$ without the MPP (cf. dark blue and yellow curves in Fig. 12a), reveals that the larger cavity produces more sound reduction near $f_{\mathrm{BPF}}$, however, with the length $L_{\mathrm{c}, 140}$, the reduction of sound appears in a broader frequency spectrum. Such a behavior is not visible in the case of the MFS setup with MPP (cf. dark blue and yellow curves in Figs. 12b). The MPP reduces broader sound reduction at $f_{\lambda / 2,1}$. Yet again, this frequency regime is not accurately represented by the simulation.

At first glance, the comparison of the RFS/MFS to RFL/MFL setup configurations shows that the tonal peaks (dashed circular area in Figs. 12b, 12d and 12f) do not 
Table 1. Measured $\left(\bar{L}_{\mathrm{P}, \text { meas }}\right)$ and simulated $\left(\bar{L}_{\mathrm{P}, \text { sim }}\right)$ overall sound pressure level at different operating points of the fan in RFS and RFL setup; MFS $(\neg \mathrm{MPP}, \ldots)$ and $\mathrm{MFL}(\neg \mathrm{MPP}, \ldots)$ setup simulation without MPP.

\begin{tabular}{|c|c|c|c|}
\hline$\dot{V}$ in $\mathrm{m}^{3} \mathrm{~s}^{-1}$ & Setup & $\bar{L}_{P, \text { meas }}$ in $\mathrm{dB}$ & $\bar{L}_{P, \text { sim }}$ in $\mathrm{dB}$ \\
\hline \multirow[t]{2}{*}{0.8} & $\mathrm{~F}, \mathrm{RFS}$ & 88.8 & 65.7 \\
\hline & $\mathrm{B}, \mathrm{RFS}$ & 85.8 & - \\
\hline \multirow[t]{2}{*}{1.0} & $\mathrm{~F}, \mathrm{RFS}$ & 79.2 & - \\
\hline & $\mathrm{B}, \mathrm{RFS}$ & 87.7 & - \\
\hline \multirow[t]{2}{*}{1.2} & $\mathrm{~F}, \mathrm{RFS}$ & 74. & - \\
\hline & $\mathrm{B}, \mathrm{RFS}$ & 92.4 & - \\
\hline \multirow[t]{2}{*}{1.4} & $\mathrm{~F}, \mathrm{RFS}$ & 71.5 & - \\
\hline & $\mathrm{B}, \mathrm{RFS}$ & 79.3 & - \\
\hline \multirow[t]{2}{*}{1.9} & F, RFS & 70.1 & - \\
\hline & $\mathrm{B}, \mathrm{RFS}$ & 69.1 & - \\
\hline- & $\mathrm{MFS}, \neg \mathrm{MPP}, L_{\mathrm{c}, 140}$ & - & 62.9 \\
\hline- & $\mathrm{MFS}, \neg \mathrm{MPP}, L_{\mathrm{c}, 200}$ & - & 62.5 \\
\hline \multirow[t]{2}{*}{0.8} & $\mathrm{~F}, \mathrm{RFL}$ & 89.1 & 65.1 \\
\hline & $\mathrm{B}, \mathrm{RFL}$ & 85.3 & - \\
\hline \multirow[t]{2}{*}{1.0} & $\mathrm{~F}, \mathrm{RFL}$ & 78.7 & - \\
\hline & $\mathrm{B}, \mathrm{RFL}$ & 87.3 & - \\
\hline \multirow[t]{2}{*}{1.2} & $\mathrm{~F}, \mathrm{RFL}$ & 72.6 & - \\
\hline & $\mathrm{B}, \mathrm{RFL}$ & 92.7 & - \\
\hline \multirow[t]{2}{*}{1.4} & $\mathrm{~F}, \mathrm{RFL}$ & 71.5 & - \\
\hline & $\mathrm{B}, \mathrm{RFL}$ & 79.8 & - \\
\hline \multirow[t]{2}{*}{1.9} & $\mathrm{~F}, \mathrm{RFL}$ & 70.4 & - \\
\hline & $\mathrm{B}, \mathrm{RFL}$ & 69.1 & - \\
\hline- & $\mathrm{MFL}, \neg \mathrm{MPP}, L_{\mathrm{c}, 140}$ & - & 63.2 \\
\hline- & $\mathrm{MFL}, \neg \mathrm{MPP}, L_{\mathrm{c}, 200}$ & - & 62.8 \\
\hline
\end{tabular}

appear so pronounced in the MFL case (cf. Figs. 13b, 13d and 13f). The dominance of the peaks is attributed to a constricted section of the tip gap due to an imperfection at the welded sheet joint (cf. Fig. 4b) and the fact that the tip gap clearance is all in all larger in the MFS case due to construction tolerances [39]. In the MFL case, the fan runs not within the MPP, but in the direct vicinity of it, thus the tip gap is not enlarged. The broadening of the tip gap results in a changed tip gap flow obviously adding to the coherent nature of the tip gap noise source. One can see by comparing Table 2 that the MFL setup produces an overall greater sound reduction at all operating points of the fan curve. The simulated sound level reduction compared to the reduction at $\dot{V}=1.9 \mathrm{~m}^{3} \mathrm{~s}^{-1}$ is the closest approximation to the cases measured. The overall sound reduction trend is qualitatively comparable to the RFS/ MFS setup, however, the simulated emission spectrum for $\dot{V}=1.4 \mathrm{~m}^{3} \mathrm{~s}^{-1}$ and $\dot{V}=1.9 \mathrm{~m}^{3} \mathrm{~s}^{-1}$ is even closer to the measurements. This time, the simulated cavity depths $L_{\mathrm{c}, 140}$ and $L_{\mathrm{c}, 200}$ represent the sound level dip at $f_{\lambda / 4,2}$ more closely. However, the frequency region near $f_{\lambda / 2,1}$ is again only poorly reproduced.

Above a frequency of $1000 \mathrm{~Hz}$, due to higher order mode propagation, the expansion chamber effect amplified by the MPP is gone and broadband sound emission reduction of roughly 2-4 $\mathrm{dB}$ can be seen at all volume flow rates (cf. Figs. 12 and 13). This corresponds to the standard transmission loss occurring for an MPP in an impedance tube.
Table 2. Measured $\left(\bar{L}_{\mathrm{P}, \text { meas }}\right)$ and simulated $\left(\bar{L}_{\mathrm{P}, \text { sim }}\right)$ overall sound pressure level at different operating points of the fan in MFS and MFL setup; MFS $(\mathrm{MPP}, \ldots)$ and MFL $(\mathrm{MPP}, \ldots)$ setup simulation with MPP and $\bar{L}_{\mathrm{P}}$-difference $\Delta(\mathrm{R} .$. - M..) between reference and MPA setup.

\begin{tabular}{|c|c|c|c|c|}
\hline $\begin{array}{l}\dot{V} \text { in } \\
\mathrm{m}^{3} \mathrm{~s}^{-1}\end{array}$ & Setup & $\begin{array}{c}\bar{L}_{\mathrm{P}, \text { meas }} \text { in } \\
\mathrm{dB}\end{array}$ & $\bar{L}_{\mathrm{P}, \text { sim }}$ in & $\begin{array}{c}\Delta \\
(\mathrm{RFS}-\mathrm{MFS})\end{array}$ \\
\hline \multirow[t]{2}{*}{0.8} & $\mathrm{~F}, \mathrm{MFS}$ & 76.8 & - & 12.0 \\
\hline & $\mathrm{B}, \mathrm{MFS}$ & 74.9 & - & 10.9 \\
\hline \multirow[t]{2}{*}{1.0} & $\mathrm{~F}, \mathrm{MFS}$ & 75.4 & - & 3.8 \\
\hline & $\mathrm{B}, \mathrm{MFS}$ & 76.0 & - & 11.7 \\
\hline \multirow[t]{2}{*}{1.2} & $\mathrm{~F}, \mathrm{MFS}$ & 72.1 & - & 1.9 \\
\hline & B, MFS & 76.1 & - & 16.3 \\
\hline \multirow[t]{2}{*}{1.4} & $\mathrm{~F}, \mathrm{MFS}$ & 69.2 & - & 2.3 \\
\hline & B, MFS & 73.0 & - & 6.3 \\
\hline \multirow[t]{2}{*}{1.9} & $\mathrm{~F}, \mathrm{MFS}$ & 67.1 & - & 3.0 \\
\hline & $\mathrm{B}, \mathrm{MFS}$ & 67.1 & - & 2.0 \\
\hline- & $\begin{array}{c}\text { MFS, MPP, } \\
L_{\mathrm{c}, 140}\end{array}$ & - & 60.4 & 5.3 \\
\hline- & $\begin{array}{c}\text { MFS, MPP, } \\
L_{\mathrm{c}, 200}\end{array}$ & - & 60.1 & 5.6 \\
\hline- & - & - & - & $\begin{array}{c}\Delta \\
(\mathrm{RFL}-\mathrm{MFL})\end{array}$ \\
\hline \multirow[t]{2}{*}{0.8} & $\mathrm{~F}, \mathrm{MFL}$ & 77.3 & - & 11.8 \\
\hline & $\mathrm{B}, \mathrm{MFL}$ & 71.9 & - & 13.4 \\
\hline \multirow[t]{2}{*}{1.0} & $\mathrm{~F}, \mathrm{MFL}$ & 73.1 & - & 5.6 \\
\hline & $\mathrm{B}, \mathrm{MFL}$ & 75.6 & - & 11.7 \\
\hline \multirow[t]{2}{*}{1.2} & $\mathrm{~F}, \mathrm{MFL}$ & 68.2 & - & 4.4 \\
\hline & $\mathrm{B}, \mathrm{MFL}$ & 78.0 & - & 14.7 \\
\hline \multirow[t]{2}{*}{1.4} & $\mathrm{~F}, \mathrm{MFL}$ & 66.8 & - & 4.7 \\
\hline & $\mathrm{B}, \mathrm{MFL}$ & 73.7 & - & 6.1 \\
\hline \multirow[t]{2}{*}{1.9} & $\mathrm{~F}, \mathrm{MFL}$ & 65.9 & - & 4.5 \\
\hline & $\mathrm{B}, \mathrm{MFL}$ & 64.2 & - & 4.9 \\
\hline- & $\begin{array}{c}\text { MFL, MPP, } \\
L_{\mathrm{c}, 140}\end{array}$ & - & 61.2 & 3.9 \\
\hline - & $\begin{array}{c}\text { MFL, MPP, } \\
L_{\mathrm{c}, 200}\end{array}$ & - & 60.8 & 4.3 \\
\hline
\end{tabular}

By comparing the simulated cases of the expansion chamber cavity with and without MPP, one can summarize that the largest portion of sound reduction is due to the cavity length and depth, hence cross-section jumps. The MPP amplifies absorption at resonance frequencies and to a small degree the reduction below the cut-off frequency (cf. blue curves in Figs. 12a and 12b and 13a and 13b). Therefore, the investigated MPP's more proper application lies rather in the higher frequency range with smaller cavity depths $L_{\mathrm{c}}$. The MPP's main benefit to the application near the fan is it's flow guiding ability. The MPP has a high flow resistance which could reduce flow through the MPP (bias flow), here, especially near the tip gap in the MFS setup. Thus, it reduces pressure drops in the fan's characteristic curve and is, as such, favorable to the fan efficiency.

\subsection{Characteristic curve results}

The results above show that the expansion chamber with and without MPP results in a reduction of the sound emitted. As mentioned before, the MPP's ability to guide the air stream and its effect on the fan performance are of 


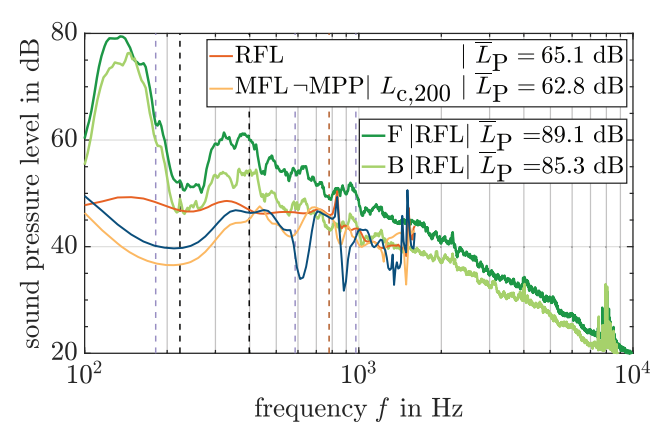

(a)

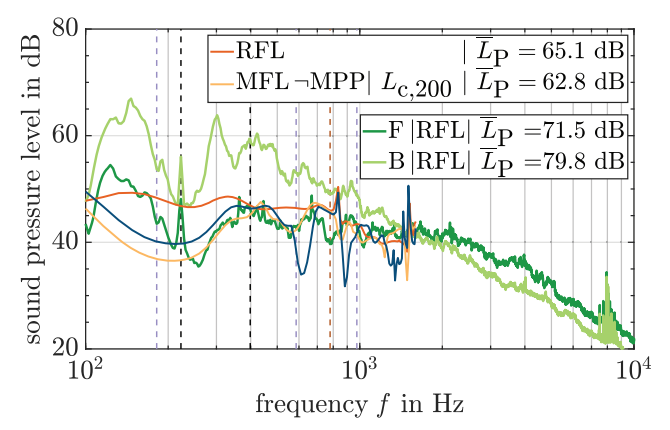

(c)

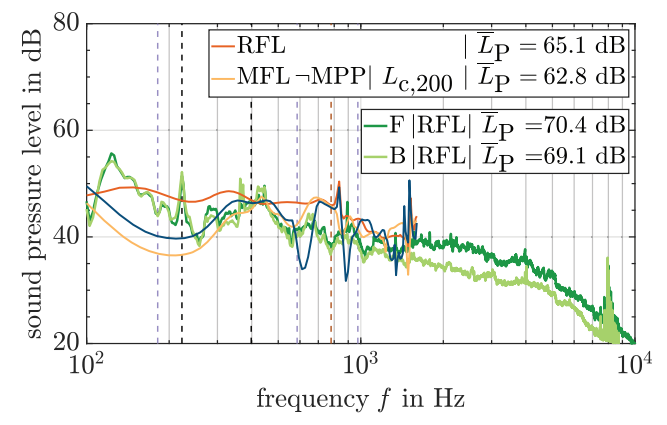

(e)

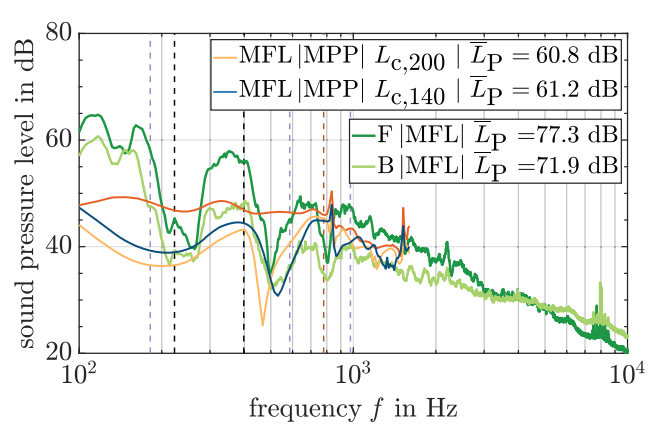

(b)

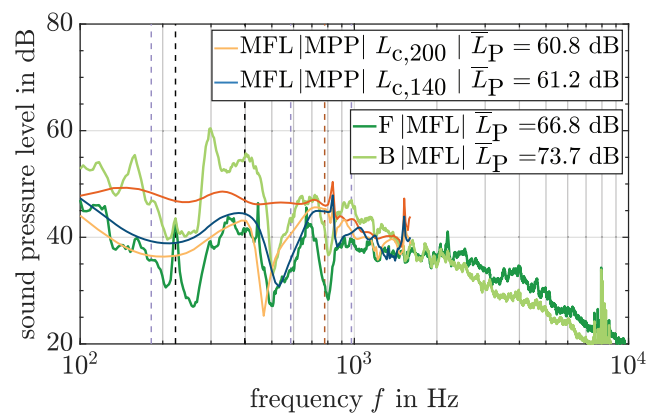

(d)

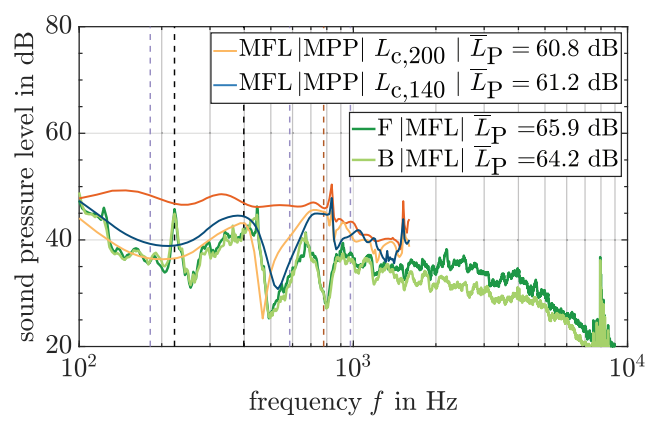

(f)

Figure 13. Measured and simulated sound emission spectra of the RFL-MFL configuration; (a, c, e) show simulated cases without MPP and in (b, d, f) the MPP is added. (a) RFL emission spectrum at $0.8 \mathrm{~m}^{3} \mathrm{~s}^{-1}$. (b) MFL emission spectrum at $0.8 \mathrm{~m}^{3} \mathrm{~s}^{-1}$. (c) RFL emission spectrum at $1.4 \mathrm{~m}^{3} \mathrm{~s}^{-1}$. (d) MFL emission spectrum at $1.4 \mathrm{~m}^{3} \mathrm{~s}^{-1}$. (e) RFL emission spectrum at $1.9 \mathrm{~m}^{3} \mathrm{~s}^{-1}$. (f) MFL emission spectrum at $1.9 \mathrm{~m}^{3} \mathrm{~s}^{-1}$.

strong interest in assessing the effectiveness of a compact axial fan sound absorber. Therefore, the fan's efficiency, pressure rise at the suction side and accumulated characteristic overall sound emission spectra are presented. In the MFS configuration, the fan is operated in the perforated section of the MPA. A larger and constricted tip gap section is present, which increases the blind flow as well as perfusion (bias flow through MPP perforations near the tip gap radially to the fan) might occur. Figure 14a demonstrates a significantly negative effect on the pressure rise of the fan and thus its efficiency. However, Figure 14b shows that in the unsteady characteristic curve regime below a volume flow rate of $1.0 \mathrm{~m}^{3} \mathrm{~s}^{-1}$, the sound reduction effects are visible for both the forward (F)- and backward (B)-skewed fan. Sound reduction is pronounced for the backward-skewed fan, since the unsteady tip gap sources are more dominant here. The overall sound pressure spectra (cf. Fig. 14b) show also that the reductions are independent of the operating point and more or less constant for the forward-skewed fan $(\mathrm{F})$ beginning at $1.0 \mathrm{~m}^{3} \mathrm{~s}^{-1}$. The simulation $(\Delta(\mathrm{RFL}-\mathrm{MFL}) \approx 5 \mathrm{~dB}$, cf. Table 2$)$ can predict the sound emission and the reduction for this frequency regime with an offset (constant sound reduction overestimation by simulation). However, this is not the case for the backwardskewed fan (B), where almost up to the design point of $1.4 \mathrm{~m}^{3} \mathrm{~s}^{-1}$, the reduction is much greater than for $(\mathrm{F})$ to drop to almost zero reduction beyond this point and then rise again to a greater reduction.

Lastly, in the case of the MFL configuration (cf. Fig. 15), the tip gap has the same size as in the reference 


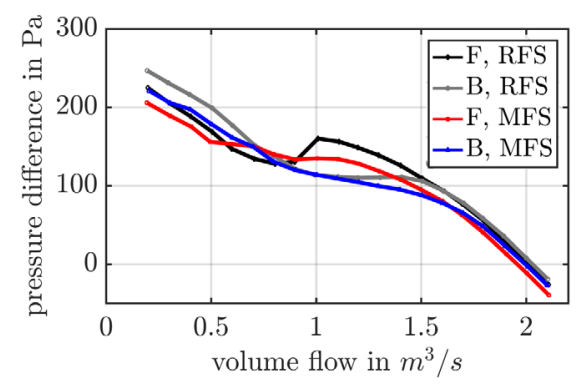

(a)

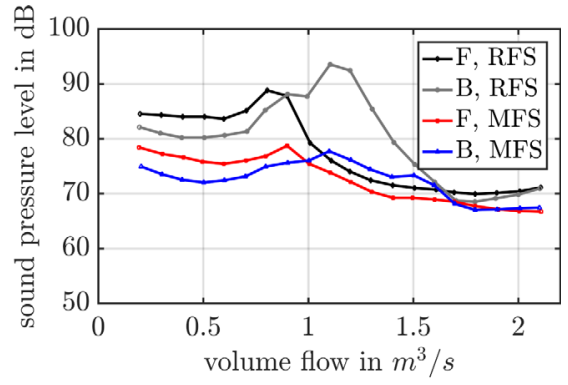

(b)

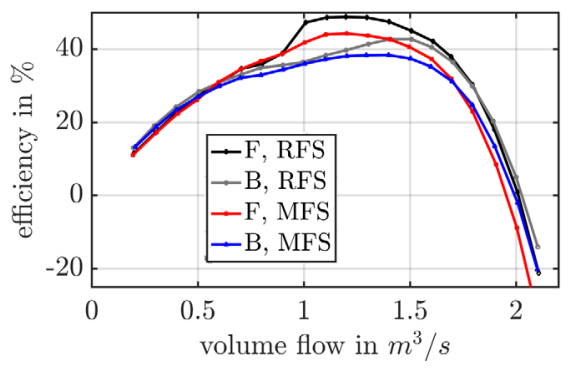

(c)

Figure 14. Fan characteristic curves for short MaPA (MFS setup). (a) Pressure rise. (b) Sound pressure level. (c) Efficiency.

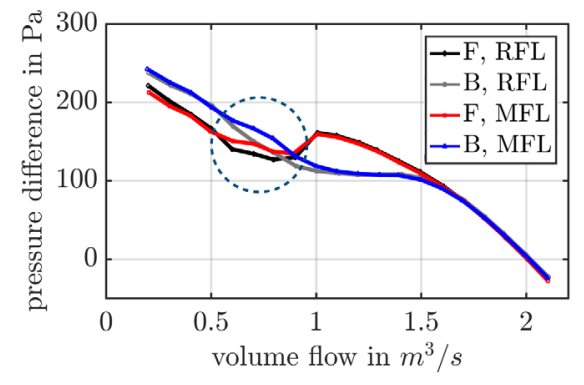

(a)

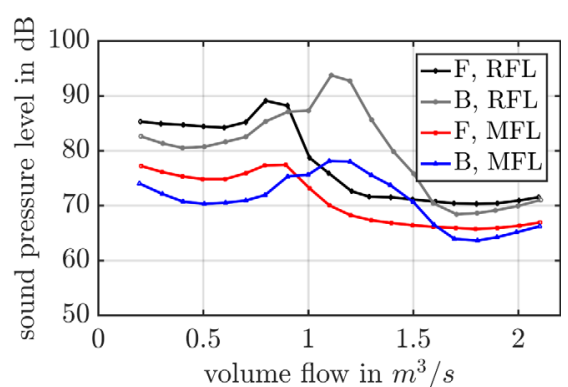

(b)

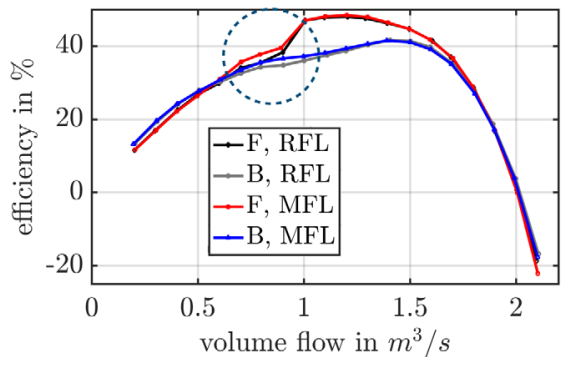

(c)

Figure 15. Characteristic curves of long MPA (MFL setup). (a) Pressure rise. (b) Sound pressure level. (c) Efficiency.

case. The pressure rise (cf. Fig. 15a) is not negatively influenced. In the partial load case, an increase in the pressure rise is visible (circular dashed bounded area), thus a positive aerodynamic effect of the MPA on the fan's efficiency curve is visible. The differences in overall sound pressures of both fans are not notably pronounced. The accumulated sound pressure spectra (cf. Fig. 15b) show that the simulation can predict the constant sound reduction $(\approx 5 \mathrm{~dB})$ of the forward-skewed fan $(\mathrm{F})$ more accurately than the reduction of the backward-skewed 
fan (B). One important conclusion to draw from Figures $14 \mathrm{~b}$ to $15 \mathrm{~b}$ is that for the RFS/RFL case, the overall sound emission is not significantly altered when the fan's distance from the nozzle is changed.

\section{Conclusion}

In this study, we have presented the simulation framework for the design of a micro-perforated absorber in the direct vicinity of a low-pressure axial fan. The simulations are based on a volume-averaging complex valued equivalent fluid model, incorporating effective MPP parameters, in combination with Finite Element simulations using non-conforming grids and fictitious acoustic point sources near the tip gap. The results are compared to experimental investigations carried out on an MPA on an axial fan test rig. The fan characteristic curves provide information about how the constructed absorber changes the efficiency and overall sound emission spectra of a backward and forward skewed fan.

It could be shown that the MPP is suitable for application in the direct vicinity of an axial fan. If the tip gap sizes compared to the reference duct arrangement can be kept the same, no negative effects on the fan's characteristic curves are detected.

It is thereby preferable to place the fan downstream of the perforations; a similar result to that in [15]. The noise reduction is greater and the effects on the characteristic curves are marginal. The apparent change in the tip gap flow (perfusion, recirculation, bias flow in radial direction of the fan) can be suppressed and the MPP sheet guides the flow.

The simulations revealed that sound emission reduction by the MPA of the forward-skewed fan can be sufficiently predicted for a volume flow rate above $1.0 \mathrm{~m}^{3} \mathrm{~s}^{-1}$. For the backward-skewed fan, a constant offset must be considered. A 1D transmission line simulation of estimated transmission loss due to cross section expansion and contraction can not accurately reflect physical reality. It does, however, ease interpretation of duct characteristic cut-off frequencies and the MPA's absorption maxima and minima. The sound pressure level spectrum dip at $f_{\lambda / 4,2}$ was sufficiently predicted. At $f_{\lambda / 2,1}$, the simulation differs quite significantly to the measurements, which suggests that the influence of the geometrical and the mechanical (vibratory back plates) boundary conditions must be further studied. Additionally, the influence of bias flow, which had been neglected in simulations, could have altered the absorption by the MPP in that particular frequency regime in the MFS setup.

The MPP amplifies resonances largely at $f_{\lambda / 4,2}$ and at $f_{\lambda / 2,1}$. At $f_{\lambda / 4,1}$ the sound reduction near $f_{\mathrm{BPF}}$ is dominated by the cavity resonance alone. At frequencies above $1000 \mathrm{~Hz}$ the micro-perforated plate increases absorption in a broadband range due to viscosity effects in the perforations themselves.

The main advantage to the MPP in the application presented lies in guiding the flow.
The compact MPA shown seems to be a well-suited concept for achieving great passive sound reduction without additional pressure loss. The experiments showed the varying effectiveness of the MPA depending on the operational point of the fan. The simulation framework allows for further reduction in computational effort by reducing the number of necessary degrees of freedom for more extensive parameter studies, for example. The MPP micro-structure could also be further studied to optimize the MPA for specific frequency ranges (below or at the blade-passing frequency) and MPP application location in the near field of the fan's sound sources (MFS case).

\section{References}

1. H. Kobayashi, J.F. Groeneweg: Effects of inflow distortion profiles on fan tone noise. AIAA Journal 18 (1980) 899-906. https://doi.org/10.2514/3.50832.

2.F.J. Krömer, S. Becker: Off-design sound emission of lowpressure axial fans under distorted inflow conditions: An experimental study. Acta Acustica United with Acustica 105 (2019) 95-108. https://doi.org/10.3813/AAA.919291.

3. T.H. Carolus, M. Stremel: Blade surface pressure fluctuations and acoustic radiation from an axial fan rotor due to turbulent inflow. Acta Acustica United with Acustica 88 (2002) 472-482.

4. F. Krömer: Sound emission of low-pressure axial fans under distorted inflow conditions. Doctoral Thesis, FAU Erlangen, 2017. https://doi.org/10.25593/978-3-96147-089-1.

5. T. Biedermann, F. Kameier, C. Paschereit: Optimized test rig for measurements of aerodynamic and aeroacoustic performance of leading edge serrations in low-speed fan application, in Proceedings of ASME Turbo Expo 2018 Turbomachinery Technical Conference and Exposition GT2018, p. GT201875369. 2018. https://doi.org/10.1115/GT2018-75369.

6. F. Krömer, F. Czwielong, S. Becker: Experimental investigation of the sound emission of skewed axial fans with leadingedge serrations. AIAA 57 (2019) 5182-5196. https://doi.org/ 10.2514/1.J058134.

7. C. Ocker, T.F. Geyer, F. Czwielong, F. Krömer, S. Becker, M. Merkel, W. Pannert: Experimental investigation of the impact of 3d-metal-printed perforated leading edges on airfoil and axial fan noise, in, in AIAA Aviation 2020 Forum, p. 2529. 2020. https://doi.org/10.2514/6.2020-2529.

8. F. Czwielong, F. Krömer, P. Chaitanya, S. Becker: Experimental investigation of the influence of different leading edge modifications on the sound emission of axial fans downstream of a heat exchanger, in Proceedings of the 23rd International Congress on Acoustics. 2019a.

9. F. Czwielong, F. Krömer, S. Becker: Sound emissions of axial fans with leading-edge serrations on different spanwise locations (vienes de 06.02), in INTER-NOISE and NOISE-CON Congress and Conference Proceedings, Vol. 259, Institute of Noise Control Engineering. 2019b, pp. 4357-4368.

10. F.J. Krömer, A. Renz, S. Becker: Experimental investigation of the sound reduction by leading-edge serrations in axial fans. AIAA Journal 56 (2018) 1-5. https://doi.org/10.2514/ 1.J056355.

11. T. Biedermann, F. Karmeier, C. Paschereit: Optimised test rig for measurements of aerodynamic and aeroacoustic performance of leading edge serrations in low-speed fan application, in Proceedings of ASME Turbo Expo 2018 Turbomachinery Technical Conference and Exposition GT2018, GT2018-75369, ASME. 2018. https://doi.org/10.1115/GT2018-75369. 
12. S. Lee: Application of microperforated elements in axial fan noise control and silencer design. Purdue University Libraries. Open Access Dissertations, 1308, 2015. https://docs.lib.purdue. edu/open access dissertations/1308; Accessed on 25.04.20.

13. S. Allam, M. Åbom: Noise reduction for automotive radiator cooling fans, in FAN 2015. 2015.

14. S. Allam, M. Åbom: Fan noise control using micro- perforated splitter silencers. Journal of Vibration and Acoustics 136 (2014) 1-8. https://doi.org/10.1115/1.4027245.

15. S. Sacks, M. Åbom: Modal filters for mitigation of in-duct sound. Acoustical Society of America 29 (2016) 1-17. https://doi/org/10.1121/2.0000473.

16. C. Schram, C. Christophe, R. Corin, H. Denayer, W. De Roeck, S. Sacks, M. Åbom: Innovative noise control in ducts, in 23th AIAA/CEAS Aeroacoustic Conference AIAA AVIATION Forum. 2017. https://doi.org/10.2514/6.2017-4038.

17. S. Floss, F. Czwielong, F. Krömer, S. Becker, M. Kaltenbacher: Achieving axial fan sound reduction with micro-perforated absorbers, in Fortschritte der Akustik - DAGA 201945. Deutsche Jahrestagung für Akustik, 18.-21. März 2019 in Rostock, DEGA-Akustik. 2019, pp. 1410-1413.

18. F. Czwielong, S. Floss, F. Krömer, S. Becker, M. Kaltenbacher: Optimierte Schallreduktion in Axialventilatorsystemen durch mikroperforierte Absorber, in Fortschritte der Akustik DAGA 2020 45. Deutsche Jahrestagung für Akustik, 16.-19. März 2020 in Hannover, DEGA-Akustik. 2020, pp. 1105-1108.

19. D.Y. Maa: Potential of micro-perforated panel absorbers. Journal of the Acoustical Society of America 104 (1998) 2861-2866. https://doi.org/10.1121/1.423870.

20. N. Atalla, F. Sgard: Modeling of perforated plates and screens using rigid frame porous media. Journal of Sound and Vibration 303 (2007) 195-208. https://doi.org/10.1016/j.jsv. 2007.01.012.

21. S. Floss, M. Kaltenbacher, G. Karlowatz: Application and simulation of micro-perforated panels in hvac systems, in Conference: 10th International Styrian Noise, Vibration \& Harshness Congress: The European Automotive Noise Conference. 2019. https://doi.org/10.4271/2018-01-1514.

22. M. Kaltenbacher, S. Floss: Nonconforming finite elements based on nitsche-type mortaring for inhomogenous wave equation, Journal of Theoretical and Computational Acoustics 26 (2018) 1850028-1-1850028-18. https://doi.org/ $10.1142 / \mathrm{S} 2591728518500287$.

23. M. Kaltenbacher: Fundamental equations of acoustics, in Computational Acoustics, Vol. 579, Springer International Publishing. 2018. https://doi.org/10.1007/978-3-319-59038-7-1.

24. M. Kaltenbacher: Numerical Simulation of Mechatronic Sensors and Actuators - Finite Elements for Computational Multiphysics, 3rd ed. Springer, Berlin, 2015. https://doi.org/ 10.1007/978-3-642-40170-1.

25. J.F. Allard: Propagation of Sound in Porous Media. Elsevier, London, 2015. https://doi.org/10.1002/9780470747339.

26. L. Jouen, F.X. Bécot: Acoustical characterization of perforated facings. Journal of the Acoustical Society of America 129 (2011) 1400-1406. https://doi.org/10.1121/1.3552887.

27. DIN EN ISO 10534: Acoustics - Determination of sound absorption coeffcient and impedance in impedance tubes Part 2: Transfer function method. Berlin Beuth Verlag, 2010.

28. J.Y. Chung, D.A. Blaser: Transfer function method of measuring in-duct acoustic properties. II. Experiment. Journal of the Acoustical Society of America 68 (1980) 914-921. https://doi.org/10.1121/1.384779.
29. J. Liu, X. Hua, D. Herrin: Estimation of effective parameters for microperforated panel absorbers and applications. Applied Acoustics 75 (2013) 86-93. https://doi.org/10.3397/1/3761043.

30. M.J. Lighthill: On sound generated aerodynamically 1: General theory. Proceedings of the Royal Society of London. Series A, Mathematical, Physical and Engineering 211 (1952) 564-587. https://doi.org/10.1098/rspa.1952.0060.

31. M. Goldstein: Unified approach to aerodynamic sound generation in the presence of solid boundaries. Acoustical Society of America 56 (1974) 497-509. https://doi.org/10.1121/1.1903283.

32. N. Curle: The influence of solid boundaries upon aerodynamic sound. Proceedings of the Royal Society of London. Series A, Mathematical, Physical and Engineering 231 (1955) 505-514. https://doi.org/10.1098/rspa.1955.0191.

33. J.E. Ffowcs Williams, D.L. Hawkings: Sound generation by turbulence and surfaces in arbitrary motion. Philosophical Transactions of the Royal Society of London. Series A, Mathematical and Physical Sciences 264 (1969) 321-342. https://doi.org/10.1098/rsta.1969.0031.

34. C. Junger: Computational aeroacoustics for the characterization of noise sources in rotating systems. Doctoral Thesis. TU Wien, 2019.

35. VDI 2081 Blatt 1: 2019-03, Air-conditioning - noise generation and noise reduction, VDI 2081. 2001.

36. E. UG: openCFS. 2020. https://www.opencfs.org/index. html. [Online; Accessed 25-December-2020].

37. M. Ainsworth: Discrete dispersion relation for hp-version finite element approximation at high wave number. IAM Journal of Numerical Analysis 42 (2004) 553-575. https://doi.org/10.1137/S0036142903423460.

38. DIN EN ISO 5801: Fan - Performance testing using standardized airways. Berlin Beuth Verlag, 2017.

39. F. Czwielong, S. Floss, S. Becker, M. Kaltenbacher: Influence of a micro-perforated duct absorber on sound emission and performance of axial fans. Applied Acoustics 174 (2020) 107746. https://doi.org/10.1016/j.apacoust.2020.107746.

40. F. Kameier, W. Neise: Rotating blade flow instability as a source of noise in axial turbomachines. Journal of Sound and Vibration 203 (1997) 833-853. https://doi.org/10.1006/jsvi.1997.0902.

41. M. Becher, R. Krusche, M. Tautz, M. Mauß, N. Springer, F.J. Krömer, S. Becker: Infleunce of the gap flow of axial vehicle cooling fans on radiated narrowband and broadband noise. Acta Acustica United with Acustica 105 (2019) 435-448. https://doi.org/10.3813/AAA.919326.

42. I.H. Abbott, A.E. Von Doenhoff: Theory of wing sections, including a summary of airfoil data. Courier Corporation. 1959.

43. F.J. Zenger, A. Renz, M. Becher, S. Becker: Experimental investigation of the noise emission of axial fans under distorted inflow conditions. Journal of Sound and Vibration 383 (2016) 124-145. https://doi.org/10.1016/j.jsv.2016.07.035.

44. F. Czwielong, F. Krömer, S. Becker: Experimental investigations of the sound emission of axial fans under influence of suction side heat exchangers, in 25th AIAA/ CEAS Aeroacoustic Conference, Vol. AIAA 2019-2618, Session: Acoustic/Fluid Dynamic Interactions X. 2019. https://doi.org/10.2514/6.2019-2618.

45. M. Möser, G. Müller: Handbook of Engineering Acoustics. Springer-Verlag Berlin Heidelberg, 2013. https://doi.org/ 10.1007/978-3-540-69460-1.

46. R. Lerch, G.M. Sessler, D. Wolf: Technische Akustik. Springer-Verlag Berlin Heidelberg, 2009. https://doi.org/ 10.1007/978-3-540-49833-9. 